\title{
The grand experiment of communism: discovering the trade-off between equality and efficiency
}

Article

Accepted Version

Farvaque, E., Mihailov, A. and Naghavi, A. (2018) The grand experiment of communism: discovering the trade-off between equality and efficiency. Journal of Institutional and Theoretical Economics, 174 (4). pp. 707-742. ISSN 0932-4569 doi: https://doi.org/10.1628/jite-2018-0003 Available at https://centaur.reading.ac.uk/74382/

It is advisable to refer to the publisher's version if you intend to cite from the work. See Guidance on citing.

To link to this article DOI: http://dx.doi.org/10.1628/jite-2018-0003

Publisher: Mohr Siebeck

All outputs in CentAUR are protected by Intellectual Property Rights law, including copyright law. Copyright and IPR is retained by the creators or other copyright holders. Terms and conditions for use of this material are defined in the End User Agreement.

www.reading.ac.uk/centaur 
Central Archive at the University of Reading

Reading's research outputs online 


\title{
The Grand Experiment of Communism: Discovering the Trade-off between Equality and Efficiency
}

\author{
Etienne Farvaque* \\ Alexander Mihailov ${ }^{\dagger}$ \\ November $2017^{\S}$ \\ Preprint of the accepted version (on 11 December 2017) \\ at the Journal of Institutional and Theoretical Economics
}

Alireza Naghavi $i^{\ddagger}$

\begin{abstract}
This paper examines how the interplay between economic incentives and social preferences transmitted by ideology plays a role in the rise and fall of communism. We introduce inequality-averse and inefficiency-averse agents and model their conflict in ideology, triggered by envy. The socioeconomic dynamics generate a pendulum-like switch from markets to a centrally-planned economy abolishing private ownership, and back to restoring market incentives. The grand experiment of communism is thus characterized to lead to the discovery of a trade-off between equality and efficiency. The model also derives conditions under which the two systems converge and become stable.
\end{abstract}

Key words: communism; inequality; inefficiency; ideology transmission; economic system transitions

JEL classification codes: C72, D31, D63, D74, D83, P51

${ }^{*}$ LEM-CNRS (UMR 921), Université de Lille, Faculté des Sciences Economiques et Sociales, Université de Lille - Sciences et Technologies, 59655 Villeneuve d'Ascq Cedex, France and CIRANO, Montréal, Québec, Canada; etienne.farvaque@univ-lille1.fr.

${ }^{\dagger}$ University of Reading, Department of Economics, Whiteknights, Reading RG6 6AA, United Kingdom; a.mihailov@reading.ac.uk.

${ }^{\ddagger}$ University of Bologna, Department of Economics, Piazza Scaravilli 2, Bologna 40126, Italy; alireza.naghavi@unibo.it.

${ }^{\S}$ We are indebted to two anonymous referees and the editor of this journal for valuable insights that substantially helped us in improving the paper. We also thank Daron Acemoglu, Toke Aidt, Wladimir Andreff, Stephen Broadberry, Mark Casson, Ron Davies, Rumen Dobrinsky, Matthias Döpke, Oded Galor, John Hartwick, Nigar Hashimzade, Hubert Kempf, Giuseppe Pignataro, Mathias Thönig, Cédric Tille, as well as the audiences at the annual meetings of the Association for Public Economic Theory (Bloomington, Indiana), Canadian Economic Association (Ottawa), Swiss Society of Economics and Statistics (Lucerne), Society for Economic Dynamics (Limassol), Workshop on States and Economic Crises (Reading), the Silvaplana Workshop on Political Economy (Pontresina), Workshop on Institutions, Economic Behavior and Economic Outcomes (Alghero), the 1st European Workshop on Political Macroeconomics (EWPM, Mainz), and seminar participants at Reading, Osaka, Bologna, Lille, Paris (OFCE), Geneva (Graduate Institute). Mihailov acknowledges funding from the University of Reading Board for Research in the Social Sciences (Project E3310100). The responsibility for any errors and misinterpretations remains our own. 
February 1848: "The Communists disdain to conceal their views and aims. They openly declare that their ends can be attained only by the forcible overthrow of all existing social conditions. Let the ruling classes tremble at a Communistic revolution. The proletarians have nothing to lose but their chains. They have a world to win." Karl Marx and Frederick Engels, Manifesto of the Communist Party. ${ }^{1}$

September 2010: "There were many odd things about my recent Havana stopover [...] but one of the most unusual was Fidel Castro's level of selfreflection. [...] I asked him if he believed the Cuban model was still something worth exporting. 'The Cuban model doesn't even work for us anymore,' he said." Jeffrey Goldberg, "Fidel: 'Cuban Model Doesn't Even Work for Us Anymore'," The Atlantic. ${ }^{2}$

\section{Introduction}

Communism was the grand experiment of the 20th century. It also seems to have been its grand illusion. In terms of utopian vision, radical implementation and socioeconomic impact, communism has left a lasting mark in history. Its rise and fall as a possible alternative to capitalism is a complex and multi-faceted theme, interpreted from different theoretical and methodological perspectives in social sciences. Works from many disciplines, going beyond politics and economics, have tried to portray or, more ambitiously, explain the various manifestations of communism across the world - from nascent and militant through mature and oppressive into stagnating and decaying.

So why another attempt to reconsider the key driving mechanisms behind the genesis of the revolutionary communist project and the gradual mass disillusionment with its realities? This paper aims at studying how the economic system affects the evolution of beliefs and preferences through the endogenous socialization efforts of the various social classes. Can this lead to cycles in economic systems, if a system gradually builds opposition to itself? To analyze these questions, we rely on economic theory to examine the interactive dynamics of economic incentives and social preferences through cultural transmission.

In what follows, we model cultural transmission as a consequence of envy with respect to inferior relative economic status, which can eventually translate into attempts to overthrow the economic system in place. The idea is based on two among the most popular theories of revolution, namely the Marxian theory (Marx, 1859 [1970]) and the relative deprivation theory (Davies, 1962; Gurr, 1970); the proponents of these theories believe that discontent leads automatically to change-oriented political action (Kuran, 1989). In other words, cultural transmission works as an intermediate mechanism linking envy to attempts for a change to a new order. The importance of social comparison and relative deprivation for organization life is also reviewed and emphasized by Olson et al. (1986) and spelled out by Taubman and Taubman (1989). The latter authors observe that to many Soviet people socialism "seems to amount to social envy, the insistence that 'my neighbor not live better than I do', even if the prospects of doing so prompts him to produce more for us both" (Mui, 1995).

To this end, we build a tractable model to formalize the role of socioeconomic factors in the process that led to the advent of communism via a forced revolution and nationalization of capital, as well as its reversal back to markets. In essence, this grand

\footnotetext{
${ }^{1}$ Chapter IV. Position of the Communists in Relation to the Various Existing Opposition Parties, translated by Samuel Moore in cooperation with Frederick Engels, 1888, http://www.marxists.org/archive/marx/works/1848/communist-manifesto/ch04.htm

${ }^{2}$ http://www.theatlantic.com/international/archive/2010/09/fidel-cuban-model-doesnt-even-workfor-us-anymore/62602/
} 
experiment resulted in gradual accumulation of experience and evidence across a few generations that revealed a trade-off between equality and efficiency in terms of productivity and saving at the scale of alternative economic systems. ${ }^{3}$ Our theoretical account of the rise and fall of communism, from the revolutionary enthusiasm of Marx and Engels through the disillusionment of Castro quoted above, is framed as a stylized game of envy triggered by inferior relative status between two types of agents involving economic decisions and transmission of ideology across generations. As we shall discuss in more detail in section 6, this is along the lines of North (2005), who interprets the experience with communism in Russia as "a story of perceived reality $\rightarrow$ beliefs $\rightarrow$ institutions $\rightarrow$ policies $\rightarrow$ altered perceived reality and on and on" (p. 4). ${ }^{4}$ The model also shows conditions under which communism remains stable that can explain the persistence and the success of the Chinese social market economy.

While the chain of logic by North (2005) is framed along purely descriptive argumentation in the tradition of the new institutional economics, it is certainly compatible with a learning perspective formalized in works such as Piketty (1995) and Buera et al. (2011), possibly combined with indoctrination (Alesina and Fuchs-Schündeln, 2007). Interestingly, recent empirical studies also provide direct evidence on the intergenerational transmission of beliefs and cultural resilience. These include Patacchini and Zenou (2016) on religion, and Dohmen et al. (2012) and Klasing (2014) on attitudes towards risk and trust and how they interact with changes in institutions.

We therefore emphasize the role of socialization and the transmission of preferences and beliefs, following a strand of literature stemming from Bisin and Verdier (2001) that explores the role of intergenerational transmission of attitudes to explain the persistence of socioeconomic status across generations. ${ }^{5}$ Our goal is to show how this same mechanism can lead to a pendulum-like swing between economic systems. Only few theoretical works focus on the interrelation between the intergenerational transmission of preferences and institutional change. The closest to our work is Döpke and Zilibotti (2008), which studies the role of the intergenerational transmission of taste for leisure and patience in the success of institutional changes brought about by the industrial revolution. Also, Saint-Paul (2010) analyzes the impact of the evolution of beliefs about the workings of the market economy on ideological bias in the society and political reform. More recently, Ticchi et al. (2013) develop a theory of endogenous regime transitions, but emphasize democratic consolidations and citizens' commitment to defend democracy against a potential military coup.

The incentive structure under the two economic systems is captured in our model by the (mis)alignment of ownership and control. This is in line with the large literature on the key weaknesses of socialism: one strand dealing with the pervasive problems arising from the 'soft budget constraints' of socialist enterprises (e.g., Kornai, 1980) - what Roemer (2008) labels 'lack of incentives'; another pointing to the overambitious task of central planning, given 'dispersed and local information', to ensure better allocative decisions than markets (e.g., von Hayek, 1940, 1945) - what Roemer (2008) labels 'lack of coordination'. Our approach highlights these two familiar disadvantages of a communist economy at their crucial link, the intertemporal optimization decision, at which the (mis)alignment of ownership and control manifests itself. The choice of consumption and accumulation out of one's own wealth given the signals of competitive markets and

\footnotetext{
${ }^{3}$ For instance, Stretton (1976) writes: "Equalities can always be ill-designed, or enforced by oppressive methods. When they are, they may reduce productivity, as well as freedom. Some communist countries have flattened their margin for skill or hard work too far, with apparently bad effect on economy efficiency."

${ }^{4}$ This view somewhat departs from earlier seminal works on communism versus capitalism, and related studies on the comparative efficiency of the two systems. Among many others, see Lange (1936 [1956]), von Hayek (1940, 1945), Tinbergen (1960), Lancaster (1973), Kornai (1980), Roemer (1980, 1985).

${ }^{5}$ See Bisin and Verdier (2010) for a survey of the literature on cultural transmission and socialization that followed.
} 
locally relevant information under capitalism sustains efficiency but generates inequality. Delegating this choice to an egalitarian planner forces equality by revolution but erodes economic efficiency, thus making everyone equal in their poverty. ${ }^{6}$

In this paper, we combine the above lines of thought and use the transmission and evolution of envy-triggered preferences to shed light on the dynamics of regime switches across economic systems. We devise a non-cooperative game between agent types that takes place in every period of an overlapping-generations (OLG) framework to demonstrate how the equilibrium strategies drive the long-run socioeconomic dynamics and can generate such pendulum-like switch from markets to an egalitarian economy abolishing private ownership, and back to rebuilding market incentives to sustain society. We focus on a large region of the world where capitalism was less developed and, perhaps more importantly, any democratization of the society was avoided or much delayed. Our model also accommodates the alternative scenario explored in Acemoglu and Robinson (2000a), where democratic reforms such as the extension of the franchise and the increase of redistribution have enabled other regions to avoid the revolutionary advent of communism.

In particular, we model two types of agents, one developing aversion towards inequality and the other towards inefficiency both as a result of envy and deprivation. Consequently, agents respond to economic incentives and transmit their values as they are affected by evolving economic outcomes. We first show how capital accumulation by the minority elite and the resulting inequality leads to increasing social discontent over time and, eventually, the overthrow of the system. We then show how a centrally-planned system aimed at equality also fades away due to misalignment of individual incentives and aggregate targets, lower well-being and productivity, and the gradual redirection of ideas towards a market system. The economic literature, and the literature on communism or social evolution more generally, has not provided so far a consistent theory on the institutional change experienced by the Soviet Union and its satellite countries in Eastern Europe throughout the 20th century accounting for both these transitions. In this consists the contribution of our stylized but history-based formal analysis of the rise and fall of communism and the conditions under which a central planning and a market system converge and stabilize.

We support our theoretical results and the underlying assumptions by providing a number of related historical (anecdotal and empirical) evidence in the relevant world regions in section 5 , focusing on the bifurcation of the transition path observed in Russia and China. We also present and discuss evidence on the incentive problem faced in centrally planned economies compared to those in which agents were free to choose output targets as well as means to meet them. In fact, the key mechanism behind the Soviet state-run system feeding inefficiency into the economy is modeled based on the findings of Cheremukhin et al. (2017) on the Soviet experience of 1928-40, in which the collectivization policies resulted in poor productivity performance in all sectors. Bergson (1991), among others, also provides figures on the remarkably lower output and consumption per worker in the Union of the Soviet Socialist Republics (USSR) compared to the rest of the world. Finally, the ideology transmission dynamics of our model also match some of the empirical findings of Alesina and Fuchs-Schündeln (2007), who explore the possibility of a feedback effect from communism on preferences by assessing the dynamics of support for state intervention among individuals in East Germany compared to those in West Germany. Looking at the preferences of different

\footnotetext{
${ }^{6}$ Note that we ignore neither that inequalities were de facto existing in communist countries, nor that they were creating resentment (see, e.g., Joo, 2005). However, considering explicitly the nomenklatura and/or unethical behavior (by the regime's own standards) as internal mechanisms of the type analyzed in Shleifer and Vishny (2002) would only complicate the model without changing the substance of the results (in effect, only accelerating the swing back from plan to market). For a 'venality'-based rent-seeking analysis of the behavior of communist leaders, see, e.g., Anderson and Boettke (1997).
} 
age groups after the reunification, they find state support to be higher in some areas for the age group whose older generation lived most of their lives before the start of communism. Support then decisively fell from one generation to the next for subsequent age groups who lived under communism. ${ }^{7}$

The paper is organized as follows. In the next section we construct our model, presenting the alternative economic systems, the types of agents, their objectives, constraints, conflict, and the transmission of their beliefs across generations. Section 3 then solves the optimization problems of the agent types in the von Stackelberg (1934 [2011], 1948 [1952]) game they play every period. Section 4 derives the intergenerational dynamics and highlights the resulting economic outcomes in terms of regime transitions or stability. Section 5 situates our theory in historical context, justifying the key assumptions we employ. The last section concludes by summarizing the insights from our model and draws parallels between our findings and the related literature. An Appendix, finally, collects our formal derivations and proofs.

\section{The Model}

\subsection{Systems and Agents}

We consider two economic systems under which society can evolve: one ('capitalist') is based on the market, denoted by $M$, and the other ('communist') on an egalitarian planner, denoted by $E$. True to the historical genesis of communist ideas, our analysis begins with a market-based system founded upon property rights over the means of production and the corresponding private incentives to capital accumulation. Our interest is in a particular region that at some point in time splits apart and experiments with communism. Alternatively, one can start with an egalitarian system in the spirit of Dow and Reed (2013), where enclosure leads to the creation of property rights for the elite, increasing inequality between insiders and outsiders. It will be made clear that in our context starting from a communist regime would deliver similar dynamics, keeping the logic of our argument unchanged.

There are two types of agents in the initial capitalist society. Its total adult population is normalized to 1 . The large majority are born without inheriting capital: they are the 'workers'. They are 'unprivileged' in the sense that they can only sell their labor force in the market in order to subsist, as Marx (1867-1894 [1967]) argued. Being the 'have-nots', they care about inequality in the capitalist society, whose victim they are by birth. We call them inequality-averse agents and denote their type as $A$. A minority of agents are born with inherited capital: they are the 'capitalists'. They extract rents from their private capital, and care about the relative inefficiency between the two systems. We call them inefficiency-averse agents and denote their type as $B .^{8}$

We consider an OLG model, where agents live for two periods. During childhood (in the first period of life), they are 'socialized' acquiring a particular type when they become adult. When mature (in the second period of life), they perform active economic and ideological roles in the society, and die at the end of the period, investing any capital wealth they have accumulated.

Under both systems, $M$ and $E$, economic power belongs to the preference type who decides upon - and enforces - the intertemporal allocation between capital accumulation and consumption. The other preference type can then only try to change the economic system through ideological influence. We denote the relative political power of each type by $q_{t}(\cdot)$ and $1-q_{t}(\cdot)$, respectively for types $A$ and $B$ in any period $t$, where $0<q_{t}(\cdot)<1$. In the related literature, this index has been defined alternatively as

\footnotetext{
${ }^{7}$ See Alesina and Fuchs-Schündeln (2007): Figure 1, p. 1516.

${ }^{8}$ See also Fehr and Schmidt $(1999,2000)$ and Olcina and Peñarrubia (2004) for alternative explanations of the agent types.
} 
either the frequency of each preference type in the total adult population (Bisin and Verdier, 2001), or the relative intensity of social resentment (Döpke and Zilibotti, 2008). It, furthermore, captures the probability of a regime shift, as introduced by Ticchi et al. (2013) in the context of political culture (in terms of 'taste' for democracy) and conflict.

\section{$2.2 \quad$ Preferences}

The lifetime utility of agent $i$ for $i=A, B$ under each system $j=M, E$ takes the form

$$
\begin{aligned}
& U^{A}\left(c_{j, t}^{A}, s_{j, t}^{A}, v_{t+1}, \tau_{t}^{A}\right)=c_{j, t}^{A}+\ln r_{j, t+1} s_{j, t}^{A}-\left(1-q_{t+1}\right) \ln v_{t+1}-\frac{\left(\tau_{t}^{A}\right)^{2}}{2}, \\
& U^{B}\left(c_{j, t}^{B}, s_{j, t}^{B}, \chi_{t+1}, \tau_{t}^{B}\right)=c_{j, t}^{B}+\ln r_{j, t+1} s_{j, t}^{B}-q_{t+1} \ln \chi_{t+1}-\frac{\left(\tau_{t}^{B}\right)^{2}}{2}
\end{aligned}
$$

where $c_{j, t}^{i}$ is the individual consumption level and $r_{j, t+1} s_{j, t}^{i}$ denotes next period interest earnings on savings that enter individual utility as a bequest left to the next generation. ${ }^{9}$ Agents also experience disutility in terms of relative economic status with respect to other individuals or the other system, depending on their type. More precisely, $v_{t+1}>1$ measures income of type $B$ relative to type $A$ or inequality within the society (eliminated under $E$, i.e., $v_{t+1}=1$ ), and $\chi_{t+1}>1$ the inefficiency of the centrally planned economy relative to free market (absent under $M$, since $\chi_{t+1}=1$ ), as perceived at $t$. Furthermore, the utility function embeds the assumption that with probability $q$ the communist system $(E)$ will be in place in the next period $t+1$, while with probability $1-q$ the market-based system $(M)$ will be in place instead. Finally, $0 \leq \tau_{t}^{i} \leq 1$ captures the cost of effort to inspire a change in the economic system, which in turn determines the probability of each regime being in place in the subsequent period, $q_{t+1}$ and $1-q_{t+1}$ for $E$ and $M$ respectively.

\subsection{Production and Income}

We consider a one-sector real model where a single good is produced using a constantreturns-to-scale linear technology. The output produced at time $t$ in regime $j$ is:

$$
H_{j, t}=\varphi_{j}\left[\alpha K_{j, t}+\theta_{j, t}(1-\alpha) L\right]
$$

for $j=M, E$ and depends on two productive factors, capital $K_{j, t}$ depreciating fully during $t$ and labor $L$ supplied inelastically by households. Workers' well-being is related to their consumption, and incentives can be measured as labor-augmenting productivity for a given amount of capital depicted by $\theta_{j, t}(c)$ with properties $\theta_{j, t}^{\prime}(c)>0$ and $\theta_{j, t}^{\prime \prime}(c)<0$ so that productivity gains are decreasing. Productivity is at its maximum level $\left(\theta_{M, t}=\right.$ 1) under a rich market-based economy, whereas it is undermined in centrally planned economy due to the low consumption allocated by the government $\left(\theta_{E, t}(c) \equiv \theta_{t}<1\right)$. In other words, the level of consumption is the result of individual work effort under markets as workers are paid their marginal product and do not suffer from the incentive problems that occur under communism. Finally, the relative importance of capital and labor in producing output are denoted by $\alpha$ and $1-\alpha$, respectively.

Under competitive factor markets, returns to labor and capital can be written as

$$
w_{M, t}=\varphi_{M}(1-\alpha)
$$

and

$$
r_{M, t}=\varphi_{M} \alpha
$$

\footnotetext{
${ }^{9}$ The inclusion of bequests in the utility function as a form of savings left as inheritance for the next generation has a long tradition in economics: since Becker (1974) and Barro (1974) altruistic individuals are believed to experience an increase in utility when they leave a bequest to their heirs.
} 
To capture densely in our model the essence of 'classical' capitalism that led to the spread of communist ideas in the late 19th century and following much of the literature, we assume a satiation consumption level $\bar{c}$, never crossed by the $A$ type so that only capital owners can invest. In the market system, income of capital owners and workers in each period is respectively

$$
y_{M, t}^{B}=r_{M, t} s_{t-1}^{B}=\varphi_{M} \alpha s_{t-1}^{B},
$$

where $s_{t-1}^{B}$ is last-period's savings that are inherited from the parental generation, and

$$
y_{M, t}^{A}=w_{M, t}=\varphi_{M}(1-\alpha) .
$$

Under communism, as capital is nationalized and capitalists are deprived of their ownership, investment decisions are no longer individual but made by the egalitarian planner. As a consequence, individual income becomes a centralized allocation of an equal share of output to each member of the society as wages, which are not necessarily equal to the marginal product of labor:

$$
y_{E, t}^{B}=y_{E, t}^{A}=w_{E, t} .
$$

Note that in this case the whole population, including $B$ types, forms the working class $\left(c_{E, t}^{A}=c_{E, t}^{B}=c_{E, t}=w_{E, t}\right)$.

Perceived income inequality arising from saving by capitalists in period $t$ is the relative income from capital versus that from labor:

$$
v_{t+1} \equiv \frac{y_{M, t+1}^{B}}{y_{M, t+1}^{A}}=\frac{\alpha}{1-\alpha} s_{t}^{B},
$$

where imposing the initial condition $y_{M, 0}^{B}>y_{M, 0}^{A}$ prevents a capitalist from switching types and becoming a worker. ${ }^{10}$

\subsection{Savings and Efficiency}

A capitalist, type $B$, chooses individual savings (which we denote by lowercase $s_{t}^{B}$ ) to maximize utility in (1) given the budget constraint

$$
c_{t}^{B}+s_{t}^{B} \leq y_{M, t}^{B} .
$$

The timing of events during the accumulation process is as follows: the savings of the previous period, $s_{t-1}^{B}$, comprise the private capital stock in the present period, $k_{M, t}$, which will then be put into production given (2). The private yields from capital ownership $y_{M, t}^{B}=r_{M, t} s_{t-1}^{B}$ generated through the production process are finally divided between consumption $c_{t}^{B}$ and savings $s_{t}^{B}$ (forming the future capital stock, $k_{M, t+1}$ ).

An egalitarian central planner instead maximizes utility (1) in the name of the type $A$ agents under the national budget constraint

$$
C_{t}+S_{t} \leq H_{E, t}
$$

The savings decision by the planner differs from private ones in that aggregate values are considered (which we denote by uppercase $S_{t}$ ). The same timing holds for the accumulation process under the communist regime: $S_{t-1}$ comprises $K_{t}$, which is used for national production along with labor and yields $Y_{t}=r_{E, t} S_{t-1}$. Total output, $H_{E, t}$,

\footnotetext{
${ }^{10}$ Note that inequality $\left(v_{t+1}\right)$ would be increasing in savings under a more general production function with imperfect substitutibility between capital and labor, regardless of capital accumulation increasing the wages in a market-based economy. See Appendix A.1 for proof.
} 
is then allocated between further savings, $S_{t}$, and aggregate consumption in the society, $C_{t}$, divided equally among all agents via identical wages assigned to all workers, $w_{E, t}=c_{E, t}$. Note that under communism there is no market price of capital, therefore $r_{E, t}$ is the shadow price of capital referred to in period $t$ by the planner.

Perceived productive inefficiency of the centralized system is expressed as distance to the 'best-practice' market frontier in terms of total returns from capital adjusted for relative labor productivity in the two regimes:

$$
\chi_{t+1} \equiv \frac{\varphi_{M} \hat{S}_{t}}{\varphi_{E} S_{t}} \frac{1}{\theta_{t+1}}
$$

where $S_{t}$ is savings by the egalitarian planner, and $\hat{S}_{t}$ a notional value of aggregate savings under a free market system referred to by individuals. This is a theoretical counterpart to Bergson's (1992) discussion of using the economy's performance regarding technical and allocative efficiency, taken together, to compare productive efficiency in the two economic systems. ${ }^{11}$

\subsection{Envy, Socialization and Regime Change}

Type $A$ agents promote a communist ideology to their next of kins upon envy against higher relative social status of type $B$ 's, while type $B$ agents advocate a pro-market ideology upon envy against a best-practice free market system. ${ }^{12}$ Socialization effort by type $A$ is therefore generated by resentment against inequality, $\tau_{t}^{A} \equiv \tau^{A}\left(v_{t}\right)$, and for type $B$ by the inferior efficiency with respect to markets $\tau_{t}^{B} \equiv \tau^{B}\left(\chi_{t}\right)$. A first channel of transmitting beliefs that captures the influence within the family in the present context is what is termed 'direct vertical transmission' in the literature (Bisin and Verdier, 2001, 2010). The evolution over time of the relative political power to change the status quo is, however, also affected outside the family: this second channel, known as 'oblique transmission', operates - in the literature as well as in our model - through the influence by peers and the broader environment (Saint-Paul, 2010).

The dynamics of the probability of a regime shift are endogenous to the current economic situation and therefore depend on the disutility experienced by each type. Endogenous socialization efforts $0 \leq \tau^{i}(\cdot) \leq 1$ affect the probability of regime change in the next generation, where the property $\tau_{t}^{i}(1)=0$ we assume states that socialization effort is only activated upon sufferance. This can also be thought of in terms of parents acting as dissidents who engage in mobilization of the next generation against the regime in power, as in Ginkel and Smith (1999). The properties of the socialization function imply that $\tau^{A}\left(v_{t}\right)=0$ under communism and $\tau^{B}\left(\chi_{t}\right)=0$ under a market economy. ${ }^{13}$ Accordingly, the law of motion is

$$
q_{M, t+1}=q_{M, t}+\left(q_{M, t}-q_{M, t}^{2}\right) \tau_{t}^{A *}
$$

under markets and

$$
q_{E, t+1}=q_{E, t}-\left(q_{E, t}-q_{E, t}^{2}\right) \tau_{t}^{B *}
$$

under communism. Thus, in the market system the relative political power of type $A$ to change the status quo, $q_{M, t+1}$, increases with any positive socialization effort by type

\footnotetext{
${ }^{11}$ The adjustment for relative labor productivity has been included in our definition as it captures a key mechanism in the model whereby an increase in individual savings under markets does not interfere with individual consumption allocations, while under communism the aggregate allocation of savings imposes lower individual consumption to all workers and undermines labor productivity. This asymmetry in the incentives to provide labor effort that has not been perceived before the experiment with communism and that has been discovered thereafter is demonstrated formally and interpreted against the historical evidence in the later sections.

${ }^{12}$ Landier et al. (2008) find empirically that ideological priors matter a lot in attitude formation.

${ }^{13}$ Derivations can be found in Appendix A.2.
} 
$A, \tau^{A}\left(v_{t}\right)>0$. Analogously, in the communist system the relative political power of type $B$ to change the status quo increases, i.e., $1-q_{E, t+1}$ increases, with any positive socialization effort by type $B, \tau^{B}\left(\chi_{t}\right)>0$.

For a successful revolution to occur, the political power of $A$-types in the society has to be higher than a certain threshold $\bar{q} \in(0,1)$. Similar to Ticchi et al. (2013), this threshold $\bar{q}$ is assumed stochastic and has a distribution $\lambda(\bar{q}) \cdot{ }^{14}$ Likewise, a transition occurs if the political power of $B$-types in the society is higher than a certain threshold $(1-\underline{q}) \in(0,1)$. This threshold $\underline{q}<\bar{q}$ is also stochastic with a distribution $\lambda(\underline{q})$. Therefore,

$$
F\left(q_{t+1}\right) \equiv \operatorname{Pr}\left(q_{t+1} \geq \bar{q}\right)=\int_{0}^{q_{t+1}} \lambda(\bar{q}) d \bar{q}
$$

represents the probability of the communist revolution being successful. Correspondingly,

$$
G\left(q_{t+1}\right) \equiv \operatorname{Pr}\left(q_{t+1} \leq \underline{q}\right)=\int_{q_{t+1}}^{1} \lambda(\underline{q}) d \underline{q}
$$

represents the probability of the transition to market taking place.

\section{Economic Systems and Within-Generation Equilibria}

We consider a sequencing of actions by type appropriate for both economic systems in the framework of a von Stackelberg leadership game played within each generation in any period $t$. The agent type who exercises ownership and control (economic power) to decide on the split between consumption and savings moves first. The other agent type can only have socialization (or political) power by instilling beliefs against the regime in force. The sequence of events at time $t$ is illustrated in Figure 1 parallel to the process of capital accumulation in the same period (see Section 2.4).

[Figure 1 about here]

\subsection{Market-Based Economy}

In the market system, capital owners control the allocation of their income between consumption and savings, to be invested and used to produce in the next period by the next generation. In contrast, workers do not own and control anything apart from their labor force, which they supply inelastically in the model. It is therefore optimal savings and capital accumulation within the capitalist 'dynasties', where ownership and control rights are aligned and effective, that drives the efficiency and sustainability of the market system but deepens the social inequality.

Type $B$ agents in this case are the first movers in the von Stackelberg leadership game and decide on savings, while taking into consideration in their maximization problem the socialization reaction of type $A$ agents to the inequality caused by their own savings. Starting with type $A$ agents (the working class), they take savings as fixed and maximize their utility using (1):

$$
\max _{\tau_{t}^{A}} U_{M, t}^{A}(\cdot)=c_{M, t}^{A}-\left(1-q_{t+1}\right) \ln v_{t+1}-\frac{\left(\tau_{t}^{A}\right)^{2}}{2} .
$$

\footnotetext{
${ }^{14}$ This is in line with the threshold model of Kuran (1989) that revolutions are unanticipated and regimes can collapse suddenly with little warning. See also Yin (1998) for a discussion of the different forms of distribution of such protest thresholds.
} 
Turning to type $B$ agents, they move first by making a decision on the amount of their savings:

$$
\begin{aligned}
& \max _{s_{t}^{B}} U_{M, t}^{B}(\cdot)=c_{M, t}^{B}+\ln y_{M, t+1}^{B}-q_{t+1} \ln \chi_{t+1}-\frac{\left(\tau_{t}^{B}\right)^{2}}{2} \\
& \text { s.t. } c_{M, t}^{B}+s_{M, t}^{B} \leq y_{M, t}^{B} .
\end{aligned}
$$

Note that savings by capitalists have no direct negative externality on aggregate productivity because the decision is made at an individual level and consumption by workers $c_{M, t}^{A}$ is not affected by it.

Savings by type $B$ as leaders and the socialization effort of type $A$ can be solved as shown in Appendix A.3. Optimal saving is

$$
s_{t}^{B *}=1-q_{t}^{2}\left(1-q_{t}\right)^{2} \ln \left(\chi_{t+1}\right),
$$

where increased expected inefficiency under the alternative (communist) system induces lower accumulation by capital owners in an effort to avoid a regime change. Observe from (13) that, for any given expected inefficiency $\chi_{t+1}(>1)$, savings are at their lowest level when the relative political power of the two types is not too different so that $q_{t}^{2}\left(1-q_{t}\right)^{2}$ is near its maximum. Optimal socialization effort is in turn

$$
\tau_{t}^{A *}=q_{t}\left(1-q_{t}\right) \ln \left(\frac{\alpha}{1-\alpha} s_{t}^{B *}\right) .
$$

Substituting $\tau_{t}^{A *}$ from (14) into (9), next-period political power of type $A$ to change the status quo becomes

$$
q_{t+1}=q_{t}+q_{t}^{2}\left(1-q_{t}\right)^{2} \ln \left(\frac{\alpha}{1-\alpha} s_{t}^{B *}\right) .
$$

It is seen from (9) and (15) that the evolution of $q_{t}$ over time under a market system is triggered when $\tau_{t}^{A *}>0$. This is true as long as

$$
v_{t+1}\left(s_{t}^{B *}\right) \equiv \frac{\alpha}{1-\alpha} s_{t}^{B *}>1,
$$

which holds as long as $y_{M, 0}^{B}>y_{M, 0}^{A}$. Recall that socialization effort aimed at a regime change is only triggered upon sufferance (for the $A$-type, for instance, $\tau_{t}^{A}>0$ if $v_{t+1}>$ 1). Hence, there is no effort to transmit preferences if labor income exceeds capital income, i.e., when the income distribution is biased in favor of workers. This is equivalent to assuming that $\tau_{t}^{A}=0$ if $v_{t+1}=\frac{y_{M, t+1}^{B}}{y_{M, t+1}^{A}} \leq 1$, which is identical to the assumption made in Mui (1995) in terms of propensity to envy. ${ }^{15}$

Lemma 1 Given the initial condition $y_{M, 0}^{B}>y_{M, 0}^{A}$, optimal individual savings by capital owners $s_{t}^{B *}$ always increase inequality, provoking type- $A$ workers into more intensive transmission of their social discontent and more effort to instigate a regime change.

Proof. See Appendix A.4.

In sum, capital owners allocate their income between consumption and savings, perpetuating inequality; workers then react by choosing their socialization effort, which in turn affects the relative political power of the next generation to change the status quo.

\footnotetext{
${ }^{15}$ Our mechanism can also be interpreted as workers effectively disliking being poor because in the utility function $\ln v_{t+1}$ appears negatively, and if (16) does not hold, that is $\ln v_{t+1}<1$, given the functional form inequality would increase the utility of the workers. Alternatively, if $\ln v_{t+1}$ appears in absolute value $\left|\ln v_{t+1}\right|$, any form of inequality would decrease their utility. In this case, increased savings caused by their socialization effort would decrease inequality, accommodating their ideology and avoiding a revolution.
} 


\subsection{Centrally-Planned Economy}

Under communism, the economic decisions are made by the egalitarian planner, who is of type $A$ and splits total consumption equally across all members of society. ${ }^{16}$ After the nationalization following the communist revolution, the society, de jure (but not de facto) owning the capital, delegates control to the egalitarian planner. Individuals do not control the choice of aggregate consumption and investment out of national income, which is also national output. Thus, under communism, there is misalignment of ownership and control rights. We capture the inefficiency that can arise from this misalignment in comparing the optimization problems under central planning (aggregate, then disaggregated top-down by equal split) vis-à-vis the market (individual, aggregated bottom-up).

The egalitarian planner is the first mover and takes into consideration the socialization reaction of type $B$ agents to the relative inefficiency of the system caused by his centralized decision. Starting with type $B$ agents (market advocates), they take savings as fixed and maximize utility according to (1):

$$
\max _{\tau_{t}^{B}} U_{E, t}^{B}(\cdot)=c_{E, t}^{B}-q_{t+1} \ln \chi_{t+1}-\frac{\left(\tau_{t}^{B}\right)^{2}}{2} .
$$

The egalitarian planner as a first mover maximizes utility in the name of the type $A$ agents taking into account aggregate values. ${ }^{17}$ Therefore, the egalitarian planner (not individual capitalists, whose capital has been nationalized) optimally chooses the level of aggregate savings, i.e., national investment. This also determines the allocation of output to be distributed equally among the total population for consumption:

$$
\begin{aligned}
\max _{S_{t}} & U_{E, t}^{A}(\cdot)=C_{t}+\ln Y_{t+1}-\left(1-q_{t+1}\right) \ln v_{t+1}-\frac{\left(\tau_{t}^{A}\right)^{2}}{2} \\
\text { s.t. } & C_{t}+S_{t} \leq H_{E, t} .
\end{aligned}
$$

Parallel to the market economy, the planner takes $Y_{t+1}$ as the value of the intergenerational transfer in his optimization problem using the shadow price of capital $r_{E, t+1}$ $\left(Y_{t+1}=r_{E, t+1} S_{t}=\varphi_{E} \alpha S_{t}\right)$.

Given the national budget $C_{t}+S_{t}=H_{E, t}$, aggregate decision making by an egalitarian planner under a communist regime affects total and per capita levels of consumption, therefore changing productivity over time. Each individual gets an identical consumption level equal to the assigned allocation by the planner

$$
c_{E, t}=\frac{H_{E, t}-S_{t}}{1}=C_{t} .
$$

Since allocation between saving and consumption takes place after production in each period, consumption in $t$ determines productivity in the following period $t+1$. There is an externality caused by productivity being a function of consumption, which is changing over time in the new economic system.

\footnotetext{
${ }^{16}$ This follows our assumption of inequality aversion characterizing type $A$ agents, to conform with the preference for equality among the thinkers and pioneers of communism. Different from maximizing social welfare, it presumes that the central planner himself experiences a disutility from inequality.

${ }^{17}$ Our choice of modeling assumption here reflects the historical realities in the formerly socialist countries. It is consistent, for example, with Kehayan and Kehayan (1978): "The Party-State claims to be the father of every citizen and claims the exclusive right to dispose of its individual happiness. [...] The concept of democracy is reduced to a false semblance of discussion channeled by the Party. [...] The silent majority lives in the waiting for a happy or unfortunate event but in any case on which it will have no hold." (p. 216, our translation from French).
} 
Lemma 2 The budget constraint of an egalitarian planner in (7), $C_{t}+S_{t}=H_{E, t}$, implies that higher aggregate savings cut consumption by the whole population. This results in a negative effect on productivity $\theta_{t+1}$ and makes the latter time-dependent.

Proof. See Appendix A.4.

If the negative externality is small enough so that savings in the egalitarian regime would increase efficiency, we are faced with a perfect communist economic system, which brings equality and increases efficiency. History has however proved otherwise and instead revealed the existence of a trade-off between equality and efficiency brought by the system. This can be observed from definition (8), where aggregate savings, $S_{t}^{*}$, increases perceived inefficiency of communism relative to markets, $\chi_{t+1}$, when its direct positive effect is dominated by its negative effect via productivity in the next period, $\theta_{t+1}$. In other words, when the egalitarian planner increases $S_{t}^{*}$ to trigger an acceleration of the accumulation process and a perceived fall in $\chi_{t+1}$, he must assign a lower consumption level to all workers according to Lemma 2. Since productivity depends positively on consumption in workers' families, next-period worker incentives and therefore productivity under communism, $\theta_{t+1}$, are reduced. If the latter effect dominates, inefficiency increases and type $B$ agents recruit intertemporally by intensifying their socialization effort. ${ }^{18}$

Lemma 3 Savings by the egalitarian planner increase inefficiency if the direct positive effect on efficiency is dominated by the indirect negative effect via next-period labor productivity $\left(\frac{\partial \chi_{t+1}}{\partial S_{t}^{*}}+\frac{\partial \chi_{t+1}}{\partial \theta_{t+1}} \frac{\partial \theta_{t+1}}{\partial S_{t}^{*}}>0\right)$, leading type $B$ agents to more intensive proliferation of market ideas to instigate transition.

Proof. See Appendix A.4.

Lemma 3 is key to our analysis and suggests that the central planner faces a trade-off between building capital through saving to ensure output growth and causing inefficiency in the subsequent period by reducing labor productivity. He must sacrifice consumption and next-period productivity to save and increase output, which may lead to more discontent in the society and an increased probability of transition. Lemma 3 introduces a mechanism that can describe the empirical findings of Cheremukhin et al. (2017), who show that while Soviet industrialization policies resulted in a significant structural change, they were disastrous in terms of productivity. In other words, despite the attempts via investments in capital, the economy did not outperform the counterfactual.

Savings by the leader and the socialization effort of type $B$ can be solved as shown in Appendix A.5. Optimal saving is

$$
S_{t}^{*}=1+q_{t}^{2}\left(1-q_{t}\right)^{2} \ln \left(v_{t+1}\right),
$$

where increased expected inequality under the alternative (market) system induces higher savings by the egalitarian planner in an effort to further consolidate the capital stock and, hence, the productive potential of the communist system. Inversely to the market system, observe from (18) that, for any given expected inequality $v_{t+1}(>1)$, savings are now at their highest when the relative political power of the two types is not too different so that $q_{t}^{2}\left(1-q_{t}\right)^{2}$ is near its maximum. Note that there is an asymmetry across regimes in that under markets savings are an individual investment based on selfinterest, and a reduction of it could be seen as a way of accommodating the demands of the opposition. Under the egalitarian regime, savings are aggregate and for the common. Increasing savings can therefore also be seen as a mode of accommodating the demands

\footnotetext{
${ }^{18}$ Lindbeck and Nyberg (2006) discuss the disincentive effects on work of welfare-state arrangements, stressing in particular that the "negative effects of the poor incentives for work in former socialist countries in Eastern Europe also seem to have materialized with a time lag".
} 
of the opposition, in an attempt to reduce inefficiency (see (21)) but without perfect information about (the extent of) its negative effect on labor productivity.

Optimal socialization effort is in turn

$$
\tau_{t}^{B *}=q_{t}\left(1-q_{t}\right) \ln \left(\frac{\varphi_{M} \hat{S}_{t}}{\varphi_{E} S_{t}^{*} \theta_{t+1}}\right) .
$$

Substituting $\tau_{t}^{B *}$ from (19) into (10), the next-period proportion of the population in favor of a market-based system becomes

$$
q_{t+1}=q_{t}-q_{t}^{2}\left(1-q_{t}\right)^{2} \ln \left(\frac{\varphi_{M} \hat{S}_{t}}{\varphi_{E} S_{t}^{*} \theta_{t+1}}\right)
$$

It immediately appears from (10) and (20) that the political power of type $A$ 's relative to type $B$ 's under the communist system weakens when $\tau_{t}^{B *}>0$. This is true as long as

$$
\chi_{t+1}\left(S_{t}^{*}\right) \equiv \frac{\varphi_{M} \hat{S}_{t}}{\varphi_{E} S_{t}^{*} \theta_{t+1}}>1,
$$

which will turn out to be the initial condition at the moment of the communist revolution, $T$, due to destruction of some fraction of the capital stock (see section 4.3.1).

[Figure 2 about here]

Given Lemma 3, aggregate savings bring about inefficiency when either $S_{t}^{*}$ or $\frac{\theta^{\prime}(c)_{t+1}}{\theta_{t+1}}$ are sufficiently large. On the other hand, the concave nature of labor-augmenting productivity as a function of consumption implies that the lagged negative effect of savings on labor productivity is large when aggregate consumption availability $C_{t}$ is limited. This can, for example, be due to a large loss of capital caused by the revolution and corresponds to the left region in Figure 2, where $c_{E, t}<c^{*}$.

With a highly elastic response of labor productivity to savings, the planner's choice of savings in the preceding period leads to a lower efficiency, and to the instability of communism derived in Lemma 3. We interpret the extent of this elasticity as the sacrifice that the population of the communist region is willing to endure in the name of an egalitarian system, i.e., to what extent their working morale is reduced by lower consumption. This tolerance may have to do with cultural values, social norms, or ideological conviction. It is, thus, ambiguous a priori, before 'experimenting' with communism to learn its magnitude across different nations or cultures, as has been confirmed from the various historical experiences with real-world socialism outlined in section 5 . In this consists, as we also discuss later, the aggregate ambiguity in our model facing a society when abolishing the market system to establish communism and the subsequent discovery of the trade-off between equality and efficiency at the scale of alternative economic systems. Finally, the limitation of output growth in a centrally-planned economy has been derived in Appendix A.6.

In sum, the egalitarian planner allocates national income between consumption and savings at the aggregate level. Type $B$ agents react by choosing their socialization effort to influence the ideology of the next generation, thus determining their share in the next period, $1-q_{t+1}$.

\section{Intergenerational Dynamics and Economic Outcomes}

In this section, we highlight our principal analytical findings derived from the dynamics of $q_{t}$ and the resulting economic outcomes. That is, having analyzed the within-period game equilibrium strategies of our two agent types, we now examine the feedback from 
relative political power $q_{t}$ to strategies across generations. Given that agents only live one period of adulthood, players in the von Stackelberg game change every period. In other words, the same game is played by each next generation, with the level of relative political power $q_{t}$ attained by socialization of agents in the previous period as the initial condition. This allows us to observe the law of motion of $q_{t}$ and potential economic transitions over time.

\subsection{Capitalism and the Communist Revolution}

We first consider the dynamics underlying the transition from a market-based to a centrally-planned economic system. We can state:

Proposition 1 (Communist Revolution) Suppose the majority type $A$ is initially stronger than type $B\left(q_{0}>0.5\right)$. Given $\tau_{t}^{A *}, s_{t}^{B *}$, and the law of motion of $q_{t}$, the optimal savings increase in $q_{t}\left(\frac{\partial s_{t}^{B *}}{\partial q_{t}}>0\right)$. This implies that a higher $q_{M, t+1}$ caused by $\tau_{t}^{A *}$ will result in more savings by type B's in the next-generation von Stackelberg game $\left(\frac{\partial s_{t+1}^{B *}}{\partial q_{t+1}}>0\right)$. As this trend continues, the probability of a communist revolution increases, and a regime change eventually occurs if $q_{t+1} \geq \bar{q}$.

Proof. See Appendix A.7.

Proposition 1 can be interpreted as follows: starting from an initial condition $q_{0}>$ 0.5 , the mobilization of the working class caused by inequality increases the political power of the next generation to overthrow the system. This induces more savings by capital owners, but increases inequality, feeding the resentment of type $A$ agents. The reinforcing effect of social resentment on capital accumulation and inequality could eventually lead the market system towards its fall. Historically, this is relevant to the case of the uprising of the working class in Russia in October 1917, on which we motivate the analysis. The intuition behind the fact that the regime in power responds contrary to the preferences of the opposition when the threat is high, exacerbating the discontent, is in line with Ginkel and Smith (1999) in that governments do not accommodate concessions to avoid signalling weakness and that mobilization is more likely to succeed under highly repressive conditions.

\subsection{Communism and the Transition to Markets}

We turn to the dynamics underlying the transition from a centrally-planned to a marketbased economic system in another proposition:

Proposition 2 (Market Transition) Observe from Proposition 1 that $q_{T}>0.5$ at the moment of revolution and suppose Lemma 3 holds. Given $\tau_{t}^{B *}, S_{t}^{*}$ and the law of motion of $q_{t}$, the optimal savings increase in $1-q_{t}\left(\frac{\partial S_{t}^{*}}{\partial q_{t}}<0\right)$. This implies that a lower $q_{E, t+1}$ caused by $\tau_{t}^{B *}$ will result in more savings by the egalitarian planner in the next-generation von Stackelberg game $\left(\frac{\partial S_{t+1}^{*}}{\partial q_{t+1}}<0\right)$. This trend continues, increasing the threat of a transition back to a market-based economy, and a regime change eventually occurs if $q_{t+1} \leq \underline{q}$.

\section{Proof. See Appendix A.8.}

Proposition 2 can be interpreted as follows: a communist system is only feasible when type $B$ 's are weaker than type $A$ 's $\left(1-q_{T}<0.5\right)$. Market propaganda that arises from lower relative efficiency under communism results in a shift of ideology in the next generation towards the market-oriented type. This induces more savings by the egalitarian planner as an attempt to restore efficiency through more investment and accumulation. Should Lemma 3 not hold, we would observe a perfect communist 
regime after the revolution that leads to reduced inequality, where the 'Big Push' holds, and sweeping state investments should increase productivity in manufacturing. The communist system would stabilize under these conditions and would gradually catch up with the rest of the world (or surpass it). However, in line with the empirical evidence in Cheremukhin et al. (2017) against the predictions of 'Big Push' theories, Lemma 3 entails the presence of a negative externality of higher saving on productivity at the aggregate level, as it is accompanied by lower available consumption and wages. Hence, responding to more discontented people by further increasing savings only exacerbates the relative inefficiency of the communist regime, making it less and less sustainable. ${ }^{19}$ As the convergence of beliefs toward the market ideology continues, the probability of economic transition increases, and the regime may eventually revert to the market system. Historically, this is relevant to the Soviet and East European case in the late 1980s and early 1990s, on which we base the analysis.

[Figure 3 about here]

Figure 3 summarizes the dynamics of the model across generations. To elucidate it, we briefly revisit the events that lead to revolution and back to transition. Under markets, initial (relative) inequality $v_{0}>1$ and capitalist savings $s_{t}^{B *}>0$ in (16) leads to $\ln \left(v_{1}\right)>0$ and $\tau_{0}^{A *}>0$ from (14), which itself brings about an increase in the relative political power of type $A$ 's in the next period $q_{1}$ through (15). According to equation (13) and Proposition 1 this increases optimal savings by capitalists in the following period, $s_{1}^{B *}$, raising inequality. This creates a continuing cycle towards a communist revolution that can be summarized as:

$$
s_{t}^{B *} \uparrow \rightarrow v_{t+1} \uparrow \rightarrow \tau_{t}^{A *} \uparrow \rightarrow q_{t+1} \uparrow \rightarrow s_{t+1}^{B *} \uparrow \rightarrow v_{t+2} \uparrow \rightarrow \tau_{t+1}^{A *} \uparrow \rightarrow q_{t+2} \uparrow \ldots
$$

until a potential revolution occurs (Proposition 1). In the case of revolution, initial (relative) inefficiency $\chi_{T}>1$ and central planner's savings $S_{t}^{*}>0$ satisfying condition (21) gives $\ln \left(\chi_{T+1}\right)>0$ and $\tau_{T}^{B *}>0$ from (19), which itself leads to a higher proportion of $B$ type agents in the following period $q_{T+1}$ through (20). According to (18) and Proposition 2, this increases optimal aggregate savings by the egalitarian planner in the following period, $S_{T+1}^{*}$, raising inefficiency with respect to the market system as long as Lemma 3 holds. This triggers a continuing cycle towards transition back to the market system that can be summarized as:

$$
S_{t}^{*} \uparrow \rightarrow \chi_{t+1} \uparrow \rightarrow \tau_{t}^{B *} \uparrow \rightarrow q_{t+1} \downarrow \rightarrow S_{t+1}^{*} \uparrow \rightarrow \chi_{t+2} \uparrow \rightarrow \tau_{t+1}^{B} * \uparrow \rightarrow q_{t+2} \downarrow \ldots,
$$

until a potential transition occurs (Proposition 2).

Corollary 1 (Stable Communism) Should market transition not occur for $q_{t}<0.5$, a substantial threat from strong type B's to overturn the regime induces the leader to accommodate his strategy in search of a compromise by decreasing aggregate savings, $S_{t}^{*}$, increasing longer-run efficiency (via higher wages and consumption) and potentially stabilizing the communist system.

\footnotetext{
${ }^{19}$ Essentially, such a set-up reflects the overinvestment experience in communist countries during their period of initial industrialization and subsequent attempts to increase future production (and, in historical context, catch up with the West). In particular, the allocation of rare resources to defense and military expenditure has been a distinctive feature of the USSR's leaders. Their behavior has been analyzed by Gifford and Kenney (1984), and famously documented by the CIA, whose work is reviewed by Maddison (1998). As the latter states: "The party elite gave highest priority to investment in heavy industry and to military spending. Consumption shares were characteristically lower than in Western countries." (p. 307). Comparative estimates of defense spending in the US and the USSR are provided by Harrison (2003), and they confirm that defense spending in the USSR was (much) higher.
} 
Proof. See Appendix A.9.

The alternative in Corollary 1 arises because for relatively strong type $B$ 's the probability of a regime change is perceived by the egalitarian planner as credible, thus the latter adapts his behavior. An increase in the probability of a regime change $\left(q_{t+1}<q_{t}\right)$ induces a reduction in aggregate savings by the egalitarian planner. This increases consumption allocations and productivity, ultimately raising efficiency of the communist system for the range of parameter values where Lemma 3 holds. By maintaining efficiency and reducing the relative political power of type $B$ 's to change the status quo, such a reaction by the egalitarian planner can prolong the communist regime and, potentially, avoid surrendering central planning. This is a 'silent' variant of the market transition case, and simply occurs once a majority of the adult population switches to a market mentality as the communist leader holds on to power but gives in and acts to increase efficiency and accommodate market advocates when $q_{t}<0.5$. The consequences coincide with a market transition as in this region either group in power tends to accommodate the opposition, and represents a shift of policy of the communist regime towards the preferences of the opposition favoring a market economy. Historically, this resembles the Chinese social market economy, where pro-market economic reforms were undertaken widely in coexistence with the centralized political system.

Recall that a transition to markets is most likely to occur when $q_{t}$ is near 0.5 where optimal saving is at its highest. If a transition occurs when $q_{t}>0.5$, then the dynamics of $q_{t}$ move towards a shift back to the previous regime. On the other hand, the regime change is more likely to persist if it occurs for lower values of $q_{t}<0.5$.

Corollary 2 (Stable Capitalism) Should transition occur when $q_{t}<0.5$, it is more likely that the market system persists since the leaders accommodate their strategy in search of a compromise by decreasing savings, $s_{t}^{B *}$, thereby mitigating inequality.

Proof. See Appendix A.9.

The alternative in Corollary 2 arises because, for relatively strong type $A$ 's perceived as credible threat of a revolution, type $B$ 's adapt their behavior. An increase in the probability of a regime change $\left(q_{t+1}>q_{t}\right)$ induces a reduction in capital accumulation by type $B$ 's. By reducing income inequality and, hence, the relative political power of type $A$ 's to change the status quo, such a reaction by capital owners can avoid slipping back towards communism. ${ }^{20}$ Historically, this seems to have been the case of social democracies and the welfare state, where democratization of capitalism and redistribution of income have preserved the market system. Moreover, if transition occurs when $q_{t}$ becomes low, then the perceived post-transition inequality $\ln \left(v_{t+1}\right)$ tends to be lower: many people are involved in the regime change as opposed to a sudden transition led by a smaller group of people as in Russia, so capital would be shared among a larger group. Therefore, there would not be much difference between communism and markets in terms of inequality: only ownership becomes private, but the wealth is in the hands of many and individual savings, $s_{t}^{B *}$, will be low.

[Figure 4 about here]

This convergence of the two polar economic systems can be thought of as either a stable market economy sustained by a large entrepreneurial middle class (Corollary 2) or a successful social market economy that applies to China (Corollary 1). The phase diagram in Figure 4 summarizes the overall dynamics of regime switches under Lemma 3 in propositions 1 and 2, and stability obtained in corollaries 1 and 2 , in the space

\footnotetext{
${ }^{20}$ Although we do not explicitly model redistribution, a part of the increase in capitalists' individual present consumption brought about by lower savings can be thought of as a transfer to the poor. This is a concept similar to Galor and Moav (2006), in which capitalists find it optimal to invest in the human capital of the poor.
} 
of consumption and the balance of power between the two types in the society. The shaded area illustrates the region of instability, where the pendulum restores force and accelerates back to communism. Looking at Figure 4, note that $B$-agents start reducing their savings (which reduces inequality) in response to an increase in the representation of $A$-types (increasing threat to the market economy) when the level of this threat is low, whereas the government in the communist regime increases savings (which increases inefficiency) in response to a rise in the representation of $B$-types (increasing threat to the system) when the level of this threat is low. The reason for this asymmetry, as we discussed earlier, is that similar to accommodating the demands of the opposition by means of decreasing individual-based savings under markets, an increase in aggregate savings for the benefit of the next generation as a whole also aims to accommodate by curtailing inefficiency, unaware of its detrimental influence on labor productivity. When Lemma 3 holds, the indirect negative effect dominates and savings increase inefficiency. This also highlights a feature of our results according to which when $A$-types are a majority in terms of political power, the economic systems are unstable and switch back and forth, whereas when $B$-types have more political power both systems move towards stability. This is driven by the cultural transmission mechanism when Lemma 3 holds, in which savings and envy reinforce each other in the former case and compensate each other in the latter.

\subsection{Regime Switches and Reallocation of Property Rights}

\subsubsection{The Moment of Communist Revolution}

To better understand the dynamics of capital accumulation, it is helpful to have a closer look at the first period immediately following the communist revolution, $T$. Aggregating all capital stock in the hands of the individual capitalists, a proportion $1-n_{T}$ of the adult population, that has been nationalized at the beginning of $T$ and taking into account the costs of the revolution in terms of a destroyed fraction of capital, $0<1-\mu_{T}<1$, we write:

$$
s_{T-1}^{B}=k_{T} \underset{\text { cost (loss) }}{\stackrel{\text { revolution }}{\Rightarrow}} \mu_{T} k_{T}=K_{T}
$$

The left-hand side of this expression is the optimal savings, $s_{T-1}^{B}$, invested into capital stock, $k_{T}$, by the individual capitalists just before the revolution and aggregated at the national level; the right-hand side is the same capital stock after accounting for the capital losses during the revolution and the nationalization of all the inherited and surviving capital, $\mu_{T} k_{T}$. The latter capital stock, $K_{T}$, is what remains for the egalitarian planner to put into production in period $T$ and, obviously, $K_{T}<k_{T}$. Note that productivity in $T$ does not change, leaving the planner with unchanged productivity that is equal to one, but a lower capital stock, $K_{T}$. This results in reduced output in $T$ relative to $T-1$, inducing the planner to increase savings in his very first intertemporal allocation decision. Such a decision could, of course, be motivated by the need to rebuild the capital base and compensate for the loss from the revolution, or to catch up with the rest of the world, as we discuss in section 5 .

From then on and under Lemma 3 , in essence, period $T+l$, for $l=1,2, \ldots$, has a lagged effect on output in period $T+l+1$ via two channels: increasing the capital stock, $K_{T+l+1}=S_{T+l}$, through more savings in the preceding period, (i) increases output, $H_{T+l+1}$, but also (ii) decreases wages and consumption that are equally assigned to all workers as from period $T$; this reduces working morale and, hence, productivity in the next period $\theta_{T+l+1}$ resulting in a lower output $H_{T+l+1}$. To sum up, if Lemma 3 holds, an elastic negative response of labor-augmenting productivity to savings across generations is ensured and communism is not sustainable in the long run. 


\subsubsection{The Post-Communist Transition Period}

By symmetry, it is also important to have a closer look into the first period immediately following the transition of the post-communist society back to a market-based system. We assume that market transition takes place through a process of privatization of the capital stock in the beginning of period $T+N$. The capital stock that has been accumulated by that time, $K_{T+N}$, is then allocated to the new capital owners, who now have to manage it, by a legal change into property rights.

As all agents are equal under communism, we assume that the share of the promarket population continues to increase upon continued socialization by opposition, so that the share who are handed the nation's capital stock at the moment of successful transition, $T+N$, just after privatization is equal to $1-n_{T+N} \equiv 1-q_{T+N}$. We thus write:

$$
S_{T+N-1}^{*}=K_{T+N} \stackrel{\text { privatization }}{\Rightarrow} k_{T+N}^{B} .
$$

The left-hand side of this expression is the optimal savings, $S_{T+N-1}^{*}$, invested into capital stock, $K_{T+N}$, by the egalitarian planner just prior to the transition to markets; it is given directly at its aggregate national level (which also coincides in our model, with a unit mass of adult population, with the per-capita mature-generation capital stock). The right-hand side of (23) is the same capital stock after transition to markets and privatization, $k_{T+N}^{B}$, to be allocated to the new capital owners and put into production in period $T+N{ }^{21}$ Individual decision-making on the split between consumption and savings by the new capital owners eliminates the negative externality in the intertemporal optimization problem typical for communism we highlighted. This allows higher output and aligns invested savings with individually-consistent decisions of capital owners. It also gradually restores the higher level of consumption characterizing the more efficient market system, yet reintroducing and perpetuating inequality.

\section{Historical Evidence}

Our model critically relies on the three following assumptions: (i) the use of aggregates in the planner's economic calculus, (ii) the lower labor-augmenting productivity delivered by a centralized economy (under Lemma 3), and (iii) the willingness of the lagging communist economy to catch-up with the market system. This section shows that these assumptions merely reflect commonly observed facts, grounding our model on historical accounts.

Our first assumption is that the calculus in a centrally-planned economy is not of consent, to paraphrase Buchanan and Tullock's (1962) well-known book title, but of command: economic decisions are taken by higher authorities, which give orders (objectives) to the lower-tier entities such as farms or plants (Ericson, 2008). A command or planned economy does not consider individual (or individual-based) decisions, but nation-wide aggregates. The debate about the virtues of market capitalism versus communist planning has received a lot of attention as early as the well documented discussion between Lange (1936 [1956]) and von Hayek (1940, 1945). Lin (2009) shows how this Soviet-style planning has endured, notably in the developing countries that have been influenced by the ideology or the country (the USSR) that largely sponsored it. Many studies confirm that what we have referred to as a misalignment of ownership and control is prevalent in such systems. Among others, Brixiová and Bulír (2003) or Bajona and Locay (2009) show that basing decisions on economic aggregates is prone to deficiencies and lower

\footnotetext{
${ }^{21}$ Similar to the moment of revolution, one can assume a certain cost of privatization in terms of the lack of entrepreneurial and managerial skills of the new capital owners or because of inheriting inefficient or outdated enterprises and equipment, so that $k_{T+N}^{B}=\mu_{T+N} K_{T+N}$.
} 
efforts by private individuals, which results in lower productivity performance. In the words of Li and Yang (2005), probably nowhere else but in China did such economic management result in a (human) disaster as large as the one during the 'Great Leap Forward' (1959-1964), which is an example of communist orthodoxy trying to harness capital to catch-up with the West.

This logically guides the choice of our second main assumption: the lower productivity of the planned economy described in Lemma 3. Although it is very difficult to compare the two systems (if only because the Net Material Product, not the GDP, was used in communist countries, excluding as a consequence the services), it has been shown that the Soviet-type economies were less productive than their Western counterparts. The USSR, for example, obtained a 2.1 per cent trend annual productivity growth per head after WWII, which compares badly with the West, even after taking into account the losses (and bounce back) due to the war (Harrison, 1998; Bergson, 1991). Broadberry and Klein (2012) confirm that the situation can be generalized to the 'Eastern bloc countries', which they compare to the EEC6 and EEC9. Wu (2001) considers the productivity of the Chinese industry, comparing it with the US, and finds that China was strongly lagging behind. Even more strikingly, he shows that the average productivity in the 1990s (i.e., after the beginning of the reforms) was almost twice larger than what had been reached since 1952. And the inferior productivity relative to market economies is commonly attributed to the deficiencies of a command economy (see, for instance, Litwak, 1993), among which the weakening workers' morale, due to low consumption possibilities (Bergson, 1991), as in our own modeling and interpretation.

The last main assumption of our analytical set-up is the willingness to catch-up with the West, an objective which historically led to overinvestment and to a focus on industry as a lever to reach that goal. USSR leaders repeatedly stated that their goal was to bring as much comfort to their population as what existed in the West (Bergson, 1991). Harrison (1985) measures the degree of overinvestment and shows this feature to be even more important in China than in the USSR, while Bergson (1991) draws the link between the insistence on industry (and especially heavy industries) and the lower consumption possibilities delivered by the Soviet economy. Easterly and Fischer (1995) go as far as attributing the decline of the Soviet economy to such overinvestment bursts. Indeed, Cheremukhin et al. (2017) use official Soviet data to show how consumption and productivity (TFP) fall under the Stalin period regardless of his efforts to cut wedges/frictions in the society. The Soviet non-agricultural TFP actually declined by about 20 per cent during its industrialization phase of 1928-40, whereas agricultural productivity recovered after an initial decline in 1928-32 but remained below its Tsarist trends.

\section{Discussion and Concluding Remarks}

Our theoretical analysis above summarized the rise and fall of communism as a process of experimenting with a new economic system that failed in most world regions, while reaching stability - under some concessions - in few others. It also showed how the same general mechanism we emphasized as driving social evolution could generate, under certain conditions and under minor regime-dependent specificity, not just the advent of communism but also its demise, or sometimes prolonged stability. That is, we proposed a model of long-run economic dynamics as one possible explanation for a principal insight from the history and the turn of events during the last century and a half. Our model blends, in effect, three lines of emerging recent literature briefly outlined next, which we could denote as (i) political economy à la Acemoglu and Robinson (2000a, 2000b, 2006); (ii) cultural transmission à la Bisin and Verdier (2001, 2010); and new institutional economics of long run change à la North (2005).

First of all, our work is in line with the few related formal accounts of political 
economy nature regarding the processes leading to successful democratization or to dictatorships succeeding democracy and vice versa in unstable societies, in particular the book by Acemoglu and Robinson (2006). Our approach is close to their framework in that we employ all of their three 'fundamental building blocks', namely:

1. 'economic-based approach', emphasizing "individual economic incentives as determining political attitudes" and that "people behave strategically in the sense of game theory" (p. xii);

2. 'the fundamental importance of conflict', where "different groups, sometimes social classes, have opposing interests over political outcomes" (p. xii);

3. 'political institutions' that "play a central role in solving problems of commitment by affecting the future distribution of de jure political power" (p. xii).

It is interesting to note as well that their example of stable democracy, Britain, corresponds to our stable capitalism under Corollary 2 and the hypothesis in Acemoglu and Robinson (2000a) that the extended franchise in the West prevented revolution. Their case of repeated cycles of democratization and dictatorship, Argentina, relates to our more general metaphor, in propositions 1 and 2, of the pendulum of economic systems. Their example of a stable nondemocratic regime, Singapore, parallels our Corollary 1, and its likely relevance to China.

Secondly, our paper also builds upon 'cultural transmission' à la Bisin and Verdier (2001, 2010), and we employ the latter expression for comparability with the rest of the literature even if the underlying mechanism in our case is not exactly the same. That is, in our model it is not cultural transmission per se that drives the results, but the combination of economic incentives and ideological beliefs with sufferance from an inferior relative status, i.e., envy (Taubman and Taubman, 1989; Mui, 1995). The paper assumes that each follower agent type compares its economic well-being to others' based on its aversion against inequality or inefficiency caused by the action of the leader. As a result, type $A$ followers suffer from inequality under markets when type $B$ is holding power and saves, whereas type $B$ followers suffer from inferior efficiency when type $A$ is holding power and saves. In our dynamic model, this mechanism is carried across generations through the transmission of preferences. Although the propensity for envy is zero in the case of higher relative status and positive otherwise, a fully rational model à la Bisin and Verdier $(2000,2001)$ would lead to the same outcome if the type living in its preferred system exerts lower effort. In the opposite scenario not studied in the model, the ruler could eventually block increasing political power of the opposition and avoid a revolution or a transition.

Thirdly, our work focuses on and attempts to formalize North's (2005) arguments regarding the process of long-run economic change, where institutions are, according to Aoki (2011), "social artifacts that cognitively mediate agents' strategic interactions and their individual beliefs in societal games". North characterizes succinctly the nature of this social evolutionary process as follows:

"In contrast to Darwinian evolutionary theory, the key to human evolutionary change is the intentionality of the players. (...) Economic change, therefore, is for the most part a deliberate process shaped by the perceptions of the actors about the consequences of their actions. The perceptions come from the beliefs of the players - the theories they have about the consequences of their actions - beliefs that are typically blended with their preferences." (North, 2005, p. viii)

Our goal with this paper was to capture the 'perceived reality $\rightarrow$ beliefs $\rightarrow$ institutions $\rightarrow$ policies $\rightarrow$ altered perceived reality' chain North (2005) emphasized in words 
into a coherent and general theoretical construct capable to highlight the social pendulum across economic systems or their convergence using the specific case of communism.

Our model begins with a perceived reality that is unjust for our type $A$ agents, as they are born unequal and poorer. Their beliefs are thus shaped out by the ideal of achieving equality, and are propagated by socialization and the spread of ideology across society. At this initial point, however, the world has never operated a communist economic system, to which the $A$ types strive. In other words, the society faces huge (aggregate) ambiguity if it decides to attempt a change in the status quo. In our model, Lemma 3 embodies the discovery of one of the dimensions of such an aggregate (or socio-economic) ambiguity, namely corresponding to the highly elastic region that implies the negative externality of savings on labor productivity under communism, unknown under markets. The communist experiment accordingly creates its own institutions and policies, forcing equality in incomes and a central planning system to replace the role of capitalists and markets. But the social realities imposed by the revolution and nationalization turn out simply not to work: all members of the communist region suffer lower and lower material well-being due to misaligned incentives resulting from a distorted ownership and control structure. By abolishing private property and market signals communism forces equality of ownership through a centralized allocation that comes at the cost of lower productivity and poor coordination. While observing as a reference point the rest of the world that has remained market-based and is performing better, a drive to promarket reforms - the altered perceived reality - reverts the society back to sustainability. Although we conclude modeling the chain of social evolution at this point, the pendulum certainly does not stop here and can either continue to swing back and forth or converge and stabilize.

Sometimes - if not often - in history, the society faces the unavoidable challenge to experiment with its own existence and future under huge ambiguity. With heterogenous agents, information sets, expectations and interests, it is not always easy to agree on a commonly shared plan, or at least hope for such a plan to possibly end up successfully. Doubts, conflicts and ideologies emerge naturally, values and institutions evolve, responding to evolving realities. At times, the experiment discovers a positive outcome. And then society finds and settles into a new equilibrium, until the next unprecedented vital change of the environment. However, when the outcome of such a social experiment is negative, the pendulum of history swings back, or rather along a spiral, whose circles constitute a gradation of hard-to-acquire learning.

\section{References}

[1] Acemoglu, Daron and James A. Robinson (2000a), "Why Did the West Extend the Franchise? Democracy, Inequality, and Growth in Historical Perspective," Quarterly Journal of Economics 115, 1167-1199.

[2] Acemoglu, Daron and James A. Robinson (2000b), "Democratization or Repression?", European Economic Review 44, 683-693.

[3] Acemoglu, Daron and James A. Robinson (2006), Economic Origins of Dictatorship and Democracy, Cambridge: Cambridge University Press.

[4] Alesina, Alberto and Nicola Fuchs-Schündeln (2007), "Good Bye Lenin (or Not?) - The Effect of Communism on People's Preferences," American Economic Review 97, 1507-1528.

[5] Anderson, Gary M. and Peter J. Boettke (1997), "Soviet Venality: A Rent-Seeking Model of the Communist State," Public Choice 93, 37-53. 
[6] Aoki, Masahiko (2011), "Institutions as Cognitive Media Between Strategic Interactions and Individual Beliefs," Journal of Economic Behavior and Organization $79,20-34$.

[7] Bajona, Claustre and Luis Locay (2009), "Entrepreneurship and Productivity: The Slow Growth of the Planned Economies," Review of Economic Dynamics 12, 505522 .

[8] Barro, Robert J. (1974), "Are Government Bonds Net Wealth?" Journal of Political Economy 82, 1095-1117.

[9] Becker, Gary S. (1974), "A Theory of Social Interactions," Journal of Political Economy 82, 1063-1093.

[10] Bergson, Abram (1991), "The USSR Before the Fall: How Poor and Why," Journal of Economic Perspectives 5, 29-44.

[11] Bergson, Abram (1992), "Communist Economic Efficiency Revisited," American Economic Review 82, 27-30.

[12] Bisin, Alberto and Thierry Verdier (2001), "The Economics of Cultural Transmission and the Dynamics of Preferences," Journal of Economic Theory 97, 298-319.

[13] Bisin, Alberto and Thierry Verdier (2010), "The Economics of Cultural Transmission and Socialization," in J. Benhabib, A. Bisin, and M. Jackson, eds., Handbook of Social Economics, Elsevier.

[14] Brixiová, Zuzana and Aleš Bulî́ (2003), "Output Performance under Central Planning: A Model of Poor Incentives," Economic Systems 27, 27-39.

[15] Broadberry, Stephen and Alexnader Klein (2011), "When and Why Did Eastern European Economies Begin to Fail? Lessons from a Czechoslovak/UK Productivity Comparison, 1921-1991," Explorations in Economic History 48, 37-52.

[16] Broadberry, Stephen and Alexander Klein (2012), "Aggregate and Per Capita GDP in Europe, 1870-2000: Continental, Regional and National Data with Changing Boundaries," Scandinavian Economic History Review 60,79-107.

[17] Buchanan, James M. and Gordon Tullock (1962), The Calculus of Consent, Ann Arbor: University of Michigan Press.

[18] Buera, Francisco J., Alexander Monge-Naranjo and Giorgio E. Primiceri (2011), "Learning the Wealth of Nations," Econometrica 79, 1-45.

[19] Cheremukhin, Anton, Mikhail Golosov, Sergei Guriev and Aleh Tsyvinski (2017), "The Industrialization and Economic Development of Russia through the Lens of a Neoclassical Growth Model," Review of Economic Studies 84, 613-649.

[20] Davies, James C. (1962), "Toward a Theory of Revolution," American Sociological Review 27, 5-19.

[21] Döpke, Matthias and Fabrizio Zilibotti (2008), "Occupational Choice and the Spirit of Capitalism," Quarterly Journal of Economics 123, 747-793.

[22] Dohmen, Thomas, Armin Falk, David Huffman and Uwe Sunde (2012), "The Intergenerational Transmission of Risk and Trust Attitudes," Review of Economic Studies 79, 645-677. 
[23] Dow, Gregory K. and Clyde G. Reed (2013), "The Origins of Inequality: Insiders, Outsiders, Elites, and Commoners," Journal of Political Economy 121, 609-641.

[24] Easterly, William and Stanley Fischer (1995), "The Soviet Economic Decline," World Bank Economic Review 9, 341-371.

[25] Ericson, Richard E. (2008), "Command Economy," in S. Durlauf and L. Blume, eds., The New Palgrave Dictionary of Economics (2nd ed.), Palgrave Macmillan.

[26] Fehr, Ernst and Klaus M. Schmidt (1999), "A Theory of Fairness, Competition, and Cooperation," Quarterly Journal of Economics 114, 817-868.

[27] Fehr, Ernst and Klaus M. Schmidt (2000), "Fairness, Incentives, and Contractual Choices," European Economic Review 44, 1057-1068.

[28] Galor, Oded and Omer Moav (2006), "Das Human-Kapital: A Theory of the Demise of the Class Structure," Review of Economic Studies 73, 85-117.

[29] Gifford, Adam Jr. and Roy W. Kenney (1984), "Socialism and the Revenue Maximizing Leviathan," Public Choice 42, 101-106.

[30] Ginkel, John and Alastair Smith (1999), "So You Say You Want a Revolution: A Game Theoretic Explanation of Revolution in Repressive Regimes," Journal of Conflict Resolution 43, 291-316.

[31] Gurr, Ted R. (1970), Why Men Rebel, Princeton, NJ: Princeton University.

[32] von Hayek, Friedrich A. (1940), "Socialist Calculation: The Competitive 'Solution'," Economica 7, 125-149.

[33] von Hayek, Friedrich A. (1945), "The Use of Knowledge in Society," American Economic Review 30, 519-530.

[34] Harrison, Mark (1985), "Investment Mobilization and Capacity Completion in the Chinese and Soviet Economies," Economics of Planning 19, 56-75.

[35] Harrison, Mark (1998), "Trends in Soviet Labour Productivity, 1928-85: War, Postwar Recovery, and Slowdown," European Review of Economic History 2, 171200.

[36] Harison, Mark (2003), "Soviet Industry and the Red Army Under Stalin: A Military-Industrial Complex?" Les Cahiers du Monde russe 44(2-3), 323-342.

[37] Joo, Hyung-min (2005), "Narratives of Inequality Under Communism: Voices from Below," Problems of Post-Communism 52, 46-58.

[38] Kehayan, Nina and Jean Kehayan (1978), Rue du prolétaire rouge, Éditions du Seuil.

[39] Klasing, Mariko (2014), "Cultural Change, Risk-Taking Behavior, and Implications for Economic Development," Journal of Development Economics 110, 158-169.

[40] Kornai, János (1980), Economics of Shortage, Amsterdam: North-Holland.

[41] Kuran, Timur (1989), "Sparks and Prairie Fires: A Theory of Unanticipated Political Revolution," Public Choice 61, 41-74.

[42] Lancaster, Kelvin (1973), "The Dynamic Inefficiency of Capitalism," Journal of Political Economy 81, 1092-1109. 
[43] Landier, Augustin, David Thesmar and Mathias Thönig (2008), "Investigating Capitalism Aversion," Economic Policy 23, 466-497.

[44] Lange, Oscar (1936 [1956]), "On the Economic Theory of Socialism," in B. Lippincott, ed., On the Economic Theory of Socialism, Minneapolis: University of Minnesota Press.

[45] Li, Wei and Dennis Tao Yang (2005), "The Great Leap Forward: Anatomy of a Central Planning Disaster," Journal of Political Economy 113, 840-877.

[46] Lin, Justin Yifu (2009), Economic Development and Transition: Thought, Strategy and Viability, New York: Cambridge University Press.

[47] Lindbeck, Assar and Sten Nyberg (2006), "Raising Children to Work Hard: Altruism, Work Norms, and Social Insurance," Quarterly Journal of Economics 121, $1473-1503$.

[48] Litwak, John M. (1993), "Coordination, Incentives, and the Ratchet Effect," RAND Journal of Economics 24, 271-285.

[49] North, Douglass C. (2005), Understanding the Process of Economic Change, Princeton and Oxford: Princeton University Press.

[50] Maddison, Angus (1998), "Measuring the Performance of a Communist Command Economy: An Assessment of the CIA Estimates for the U.S.S.R.," Review of Income and Wealth 44, 307-323.

[51] Marx, Karl (1867-1894 [1967]), Capital, 3 vols, New York: International Publishers.

[52] Marx, Karl (1859 [1970]), A Contribution to the Critique of Political Economy, New York: International Publishers.

[53] Mui, Vai-Lam (1995), "The Economics of Envy," Journal of Economic Behavior and Organization 26, 311-336.

[54] Olcina, Gonzalo and Concepción Peñarrubia (2004), "Hold up and Intergenerational Transmission of Preferences," Journal of Economic Behavior and Organization 54, $111-132$.

[55] Olson, James M., C. Peter Herman, and Mark P. Zanna, eds. (1986), Relative Deprivation and Social Comparison: The Ontario Symposium, Vol. 4, London: Lawrence Erlbaum Associates, Publishers.

[56] Patacchini, Eleonora and Yves Zenou (2016), "Social Networks and Parental Behavior in the Intergenerational Transmission of Religion," Quantitative Economics 7, 969-995.

[57] Piketty, Thomas (1995), "Social Mobility and Redistributive Politics," Quarterly Journal of Economics 110, 551-584.

[58] Roemer, John E. (1980), "A General Equilibrium Approach to Marxian Economics," Econometrica 48, 505-530.

[59] Roemer, John E. (1985), "Rationalizing Revolutionary Ideology," Econometrica 53, 85-108.

[60] Roemer, John E. (2008), "Socialism," in S. Durlauf and L. Blume, eds., The New Palgrave Dictionary of Economics (2nd ed.), Palgrave Macmillan. 
[61] Saint-Paul, Gilles (2010), "Endogenous Indoctrination: Occupational Choices, the Evolution of Beliefs and the Political Economy of Reforms," Economic Journal 120, $325-353$.

[62] Shleifer, Andrei and Robert Vishny (2002), The Grabbing Hand, Harvard University Press.

[63] von Stackelberg, Heinrich F. (1934 [2011]), Marktform und Gleichgewicht [Market Structure and Equilibrium], Verlag von Julius Springer, Berlin; Heidelberg; New York, NY / Vienna [Springer (transl. by Damien Bazin)].

[64] von Stackelberg, Heinrich F. (1948 [1952]), Grundlagen der theoretischen Volkswirtschaftslehre [The Theory of the Market Economy], Francke, London /Bern [William Hodge (transl. by Alan T. Peacock)].

[65] Stretton, Hugh (1976), Capitalism, Socialism, and the Environment, Cambridge: Cambridge University Press.

[66] Taubman, William and Jane Taubman (1989), Moscow Spring, New York: Summit Books.

[67] Ticchi, Davide, Thierry Verdier and Andrea Vindigni (2013) "Democracy, Dictatorship and the Cultural Transmission of Political Values," IZA Discussion Paper 7441.

[68] Tinbergen, Jan (1960), "Optimum Savings and Utility Maximization over Time," Econometrica 28, 481-489.

[69] Wu, Harry Xiaoying (2001), "China's Comparative Labour Productivity Performance in Manufacturing, 1952-1997: Catching Up or Falling Behind?", China Economic Review 12, 162-189.

[70] Yin, Chien-Chung (1998), "Equilibria of Collective Action in Different Distributions of Protest Thresholds," Public Choice 97, 535-567.

\section{A Appendix (for online publication)}

\section{A.1 Inequality under a More General CES Production Function}

In order to check the validity of our argument under a more general case, we have assessed it using a constant elasticity of substitution (CES) production function, as follows.

The output produced at time $t$ in regime $j$ is:

$$
H_{j, t}=\varphi_{j}\left[\alpha K_{j, t}^{\rho}+(1-\alpha)\left(\theta_{j, t} L\right)^{\rho}\right]^{\frac{1}{\rho}},
$$

for $j=M, E$, where $\rho$ is the degree of substitutability between the two inputs.

Under competitive factor markets, returns to labor and capital can then be written as

$$
w_{M, t}=\varphi_{M}^{\frac{1}{1-\rho}} H_{M, t}^{1-\rho}(1-\alpha) \theta_{M, t}^{\rho} L^{\rho-1}
$$

and

$$
r_{M, t}=\varphi_{M}^{\frac{1}{1-\rho}} H_{M, t}^{1-\rho} \alpha K_{M, t}^{\rho-1} .
$$

Next, we measure inequality as in the main text using the above values for the marginal product of labor and capital. Doing so leads to

$$
v_{t+1} \equiv \frac{y_{M, t+1}^{B}}{y_{M, t+1}^{A}}=\frac{\alpha K_{M, t+1}^{\rho}}{\theta_{M, t}^{\rho} L^{\rho-1}}=\frac{\alpha}{L^{\rho-1}} K_{M, t+1}^{\rho},
$$


recalling that the income of type- $B$ agents under free market is equal to $y_{M, t+1}^{B}=$ $r_{M, t+1} s_{t}^{B}$. As a result, although increased capital accumulation will increase wages in a market-based economy, income inequality (and thus the threat to the system) will increase despite the reduced marginal returns to capital because of a larger accumulated capital stock. Note also that $\theta_{M, t}=1$ holds throughout the paper to account for the fact that incentives are at their maximum level under a market economy.

\section{A.2 Intergenerational Transmission Mechanism}

The socialization process of the agents of each type, $A$ and $B$, can be summarized as follows: the transition probabilities at time $t, P_{t}^{i j}$, that a parent of type $i$ has a child with a stronger or weaker relative political power can be written as

$$
\begin{aligned}
P_{t}^{A A} & =\tau_{t}^{A *}+\left(1-\tau_{t}^{A *}\right) q_{t} ; \\
P_{t}^{A B} & =\left(1-\tau_{t}^{A *}\right)\left(1-q_{t}\right) ; \\
P_{t}^{B B} & =\tau_{t}^{B *}+\left(1-\tau_{t}^{B *}\right)\left(1-q_{t}\right) \\
P_{t}^{B A} & =\left(1-\tau_{t}^{B *}\right) q_{t} .
\end{aligned}
$$

Given these transition probabilities, the relative political power of individuals of type $A$ in period $t+1$ is

$$
\begin{aligned}
q_{t+1} & =q_{t} P_{t}^{A A}+\left(1-q_{t}\right) P_{t}^{B A} \\
& =q_{t}+\left(q_{t}-q_{t}^{2}\right)\left(\tau_{t}^{A *}-\tau_{t}^{B *}\right) .
\end{aligned}
$$

\section{A.3 Solving the Market-Based Economy}

Replacing for $v_{t+1}$ from (5) and for $q_{M, t+1}$ from (9), the optimization problem becomes:

$$
\max _{\tau_{t}^{A}} \quad c_{M, t}^{A}-\left\{1-\left[q_{t}+q_{t}\left(1-q_{t}\right) \tau_{t}^{A}\right]\right\} \ln \left(\frac{\alpha}{1-\alpha} s_{t}^{B}\right)-\frac{\left(\tau_{t}^{A}\right)^{2}}{2} .
$$

The first-order condition yields the optimal reaction of type $A$ as follower:

$$
\begin{aligned}
\frac{\partial U_{M, t}^{A}(\cdot)}{\partial \tau_{t}^{A}} & =q_{t}\left(1-q_{t}\right) \ln \left(\frac{\alpha}{1-\alpha} s_{t}^{B}\right)-\tau_{t}^{A}=0 \\
& \Leftrightarrow \tau_{t}^{A *}=q_{t}\left(1-q_{t}\right) \ln \left(\frac{\alpha}{1-\alpha} s_{t}^{B}\right) .
\end{aligned}
$$

This equation delivers a preliminary insight on the mechanisms that drive the evolution from one system to another. An increase in private savings (by the capitalists) leads to increased socialization effort by type $A$ agents. The latter can only expect a growing inequality between the two types of agents, which reinforces their determination to instill their values in the next generation, and to potentially change the regime. More precisely, the higher the expected inequality generated by type $B$ private savings, the higher the effort of type $A$ to transmit their preferences towards a more equal society.

Turning to the problem of type $B$, after a series of substitutions and omitting the $M$-subscript to savings due to the absence of individual savings under communism in our model, we rewrite

$$
\max _{s_{t}^{B}} \varphi_{M} \alpha s_{t-1}^{B}-s_{t}^{B}+\ln \left(\varphi_{M} \alpha s_{t}^{B}\right)-\left[q_{t}+\left(q_{t}-q_{t}^{2}\right) \tau_{t}^{A *}\right] \ln \left(\chi_{t+1}\right) .
$$


Replacing for $\tau_{t}^{A *}$ with the optimal reaction of type $A$ agents from (A1) and taking the first-order condition yields optimal savings by type $B$ as leader,

$$
\begin{aligned}
\frac{\partial U_{M, t}^{B}(\cdot)}{\partial s_{t}^{B}} & =-1+\frac{1}{s_{t}^{B}}-\frac{q_{t}^{2}\left(1-q_{t}\right)^{2}}{s_{t}^{B}} \ln \left(\chi_{t+1}\right)=0 \\
& \Leftrightarrow s_{t}^{B *}=1-q_{t}^{2}\left(1-q_{t}\right)^{2} \ln \left(\chi_{t+1}\right),
\end{aligned}
$$

where the second-order condition to ensure a maximum is always satisfied.

\section{A.4 Proof of Lemmas}

\section{A.4.1 Lemma 1}

See equation (16) where $\frac{\partial v_{t+1}}{\partial s_{t}^{B *}}>0$ increases $\tau_{t}^{A *}$ in (14) and $q_{t+1}$ in (15).

\section{A.4.2 Lemma 2}

We can conclude from (17) and the properties of $\theta_{t+1}$ that

$$
\frac{\partial \theta_{t+1}}{\partial S_{t}^{*}}=-\frac{\partial \theta_{t+1}}{\partial C_{t}}=-\frac{\partial \theta_{t+1}}{\partial c_{E, t}} \equiv-\theta^{\prime}(c)_{t+1}<0 .
$$

\section{A.4.3 Lemma 3}

Inefficiency in period $t+1$ increases if the direct positive effect of saving in $t$ on efficiency in $t+1$ is dominated by its negative lagged effect on labor productivity via a reduction in $\theta_{t+1}$ :

$$
\underbrace{\frac{\partial \chi_{t+1}}{\partial \theta_{t+1}} \frac{\partial \theta_{t+1}}{\partial S_{t}^{*}}}_{-}>|\underbrace{\frac{\partial \chi_{t+1}}{\partial S_{t}^{*}}}_{-}|,
$$

where we know $\frac{\partial \theta_{t+1}}{\partial S_{t}^{*}}<0$ from Lemma 2 . This condition holds if and only if

$$
\frac{\theta^{\prime}(c)_{t+1}}{\theta_{t+1}}>\left|-\frac{1}{S_{t}^{*}}\right|
$$

\section{A.5 Solving the Centrally-Planned Economy}

Replacing for $\chi_{t+1}$ from (8) and for $q_{E, t+1}$ from (10), the optimization problem becomes:

$$
\max _{\tau_{t}^{B}} c_{E, t}^{B}-\left[q_{t}+q_{t}\left(1-q_{t}\right)\left(-\tau_{t}^{B}\right)\right] \ln \left(\frac{\varphi_{M} \hat{S}_{t}}{\varphi_{E} S_{t} \theta_{t+1}}\right)-\frac{\left(\tau_{t}^{B}\right)^{2}}{2} .
$$

The first-order condition then yields:

$$
\begin{aligned}
\frac{\partial U_{E, t}^{B}(\cdot)}{\partial \tau_{t}^{B}} & =q_{t}\left(1-q_{t}\right) \ln \left(\frac{\varphi_{M} \hat{S}_{t}}{\varphi_{E} S_{t} \theta_{t+1}}\right)-\tau_{t}^{B}=0 \\
& \Leftrightarrow \tau_{t}^{B *}=q_{t}\left(1-q_{t}\right) \ln \left(\frac{\varphi_{M} \hat{S}_{t}}{\varphi_{E} S_{t} \theta_{t+1}}\right) .
\end{aligned}
$$

Hence, an increase in the planner's aggregate savings directly reduces the socialization effort by type $B$ agents. This is due to the fact that, as seen in (8), such an increase is perceived to give a boost to the efficiency of the communist system. While this effect 
per se could reduce inefficiency, it will be seen below that the command accumulation process has a negative externality on labor productivity, leaving the total effect of aggregate savings on the relative efficiency of the communist system and the socialization effort by type $B$ agents ambiguous. ${ }^{22}$

Turning to the problem of the planner, after a series of substitutions, we obtain:

$$
\max _{S_{t}} \varphi_{E}\left[\alpha S_{t-1}+\theta_{t}(1-\alpha) L\right]-S_{t}+\ln \left(\varphi_{E} \alpha S_{t}\right)-\left\{1-\left[q_{t}-\left(q_{t}-q_{t}^{2}\right) \tau_{t}^{B}\right]\right\} \ln \left(v_{t+1}\right) .
$$

Replacing for $\tau_{t}^{B}$ with the optimal reaction curve by type $B$ agents derived in (A2) and taking the first-order condition yields:

$$
\begin{aligned}
\frac{\partial U_{E, t}^{A}(\cdot)}{\partial S_{t}} & =-1+\frac{1}{S_{t}}+q_{t}^{2}\left(1-q_{t}\right)^{2} \ln \left(v_{t+1}\right)\left[\frac{1}{S_{t}}-\frac{\theta^{\prime}(c)_{t+1}}{\theta_{t+1}}\right]=0 \\
& \Leftrightarrow \quad S_{t}^{*}=\frac{1+q_{t}^{2}\left(1-q_{t}\right)^{2} \ln \left(v_{t+1}\right)}{1+\tilde{\eta}_{\theta_{t+1}} q_{t}^{2}\left(1-q_{t}\right)^{2} \ln \left(v_{t+1}\right)},
\end{aligned}
$$

where $\tilde{\eta}_{\theta_{t+1}}$ represents the perceived lagged semi-elasticity of labor productivity in $t+1$ with respect to consumption in $t$, i.e., $\frac{\theta^{\prime}(c)_{t+1}}{\theta_{t+1}}$. In the rest of the analysis, we assume imperfect information, i.e., $\tilde{\eta}_{\theta_{t+1}} \neq \eta_{\theta_{t+1}}$, with $\eta_{\theta_{t+1}}$ denoting the actual lagged semielasticity of labor productivity in $t+1$ with respect to consumption in $t$, about the extent to which this value can be observed to analyze the different consequences of a centralized regime. ${ }^{23}$

Solving out the inequality in Lemma 3 and replacing for optimal savings from (A3) shows that in order for the lemma to hold the condition

$$
\eta_{\theta_{t+1}}>\frac{1+\tilde{\eta}_{\theta_{t+1}} q_{t}^{2}\left(1-q_{t}\right)^{2} \ln \left(v_{t+1}\right)}{1+q_{t}^{2}\left(1-q_{t}\right)^{2} \ln \left(v_{t+1}\right)}
$$

must be satisfied. This condition suggests that savings made at an aggregate level are more likely to increase inefficiency the larger is the actual lagged impact of saving on labor productivity, $\eta_{\theta_{t+1}}$, and the smaller is that predicted by the central planner, $\tilde{\eta}_{\theta_{t+1}}$. This would be in line with stylized facts provided in Brixiová and Bulír (2003) on how (i) the planning authority did not know the true production function of individual firms and their capacity utilization, and (ii) firms had vested interest to hide this information, while the planner possessed only primitive monitoring technology. Knowing this and without loss of generality, we set $\tilde{\eta}_{\theta_{t+1}}=0$ in the remainder of the analysis in order to study the above-mentioned caveat of the communist system. Otherwise, a planner with perfect information $\left(\tilde{\eta}_{\theta_{t+1}}=\eta_{\theta_{t+1}}\right)$ will not undermine the sustainability of the economic system, delaying or avoiding transition to markets.

With $\tilde{\eta}_{\theta_{t+1}}=0$, equation (A3) becomes

$$
S_{t}^{*}=1+q_{t}^{2}\left(1-q_{t}\right)^{2} \ln \left(v_{t+1}\right),
$$

where the second-order condition to ensure a maximum is always satisfied.

\footnotetext{
${ }^{22}$ This ambiguity resembles historical evidence such as that in Broadberry and Klein (2011), who show Czechoslovakia's comparative productivity position under the central planning regime with respect to the UK to have initially improved before falling back to lower levels.

${ }^{23}$ The ambiguity the central planner faces lies hidden in the productivity function. While the negative dependence of productivity on lagged consumption is known, the magnitude of this effect is uncertain, implying that agents do not have perfect foresight or complete information, although they are effectively rational in the context of the game they play.
} 


\section{A.6 Output Growth in the Centrally-Planned Economy}

Recalling $S_{t}^{*}=K_{t+1}$ and substituting $S_{t}^{*}$ into the production function in (2), we get an expression for next period output in terms of optimal savings:

$$
H_{E, t+1}\left(S_{t}^{*}\right)=\varphi_{E}\left\{\alpha\left[1+q_{t}^{2}\left(1-q_{t}\right)^{2} \ln \left(v_{t+1}\right)\right]+\theta_{t+1}(1-\alpha) L\right\} .
$$

The equation shows that the strong negative externality of savings on labor productivity in the command economy under Lemma 3 also prevents production $H_{E, t}$ in (2) from growing over time. This rules out the possibility of investment creating higher consumption possibilities over time by raising total output. ${ }^{24}$

\section{A.7 Proof of Proposition 1}

We derive the effect of the relative political power of workers in some period $t$ on the saving behavior of the capital owners in that period:

$$
\frac{\partial s_{t}^{B *}}{\partial q_{t}}=2 q_{t}\left(1-q_{t}\right)\left(2 q_{t}-1\right) \ln \left(\chi_{t+1}\right)\left\{\begin{array}{cc}
<0 & \text { if } q_{t}<0.5 \\
>0 & \text { if } q_{t}>0.5
\end{array} .\right.
$$

Thus, for any high $q_{t}>0.5$, we have $\frac{\partial s_{t}^{B *}}{\partial q_{t}}>0$. In words, the optimal reaction functions of the two types in the von Stackelberg game under markets lead to a progressive increase of $q_{t}$. Type $A$ 's become increasingly strong to overthrow the existing capitalist social order. In each period $t$ a communist revolution may occur with probability $q_{t}$.

\section{A.8 Proof of Proposition 2}

We derive the effect of the relative political power of market advocates in some period $t$ on the saving behavior of the egalitarian planner in that period:

$$
\frac{\partial S_{t}^{*}}{\partial q_{t}}=-2 q_{t}\left(1-q_{t}\right)\left(2 q_{t}-1\right) \ln \left(v_{t+1}\right)\left\{\begin{array}{ll}
>0 & \text { if } q_{t}<0.5 \\
<0 & \text { if } q_{t}>0.5
\end{array} .\right.
$$

Thus, for any high $q_{t}>0.5$ (i.e., any low $1-q_{t}<0.5$ ), $\frac{\partial S_{t}^{*}}{\partial q_{t}}<0$ (i.e., $\frac{\partial S_{t}^{*}}{\partial\left(1-q_{t}\right)}>0$ ). In words, the optimal reaction functions of the two types in the von Stackelberg game under communism lead to a progressive decrease of $q_{t}$. In each period $t$ a pro-market transition may occur with probability $1-q_{t}$.

\section{A.9 Proof of Corollaries}

\section{A.9.1 Corollary 1}

When $q_{t}<0.5$, type $B$ 's become sufficiently strong to represent a credible threat to bring down communism. Consequently, the optimal aggregate savings, $S_{t}^{*}$, becomes increasing in $q_{t}$ (that is, decreasing in $1-q_{t}$ ). See the proof of Proposition 2.

\section{A.9.2 Corollary 2}

When $q_{t}<0.5$, type $B$ leaders decrease savings, $s_{t}^{B *}$, as a response to a higher $q_{t}$, potentially stabilizing the market system. See the proof of Proposition 1.

\footnotetext{
${ }^{24}$ For an insight on the reduced consumption opportunities delivered by communist regimes, see for example Bergson (1991).
} 


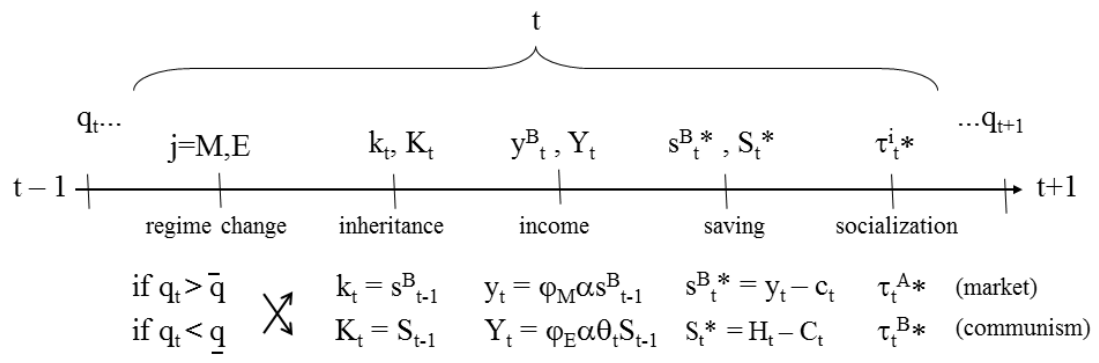

Figure 1: Sequence of Events in Period $t$

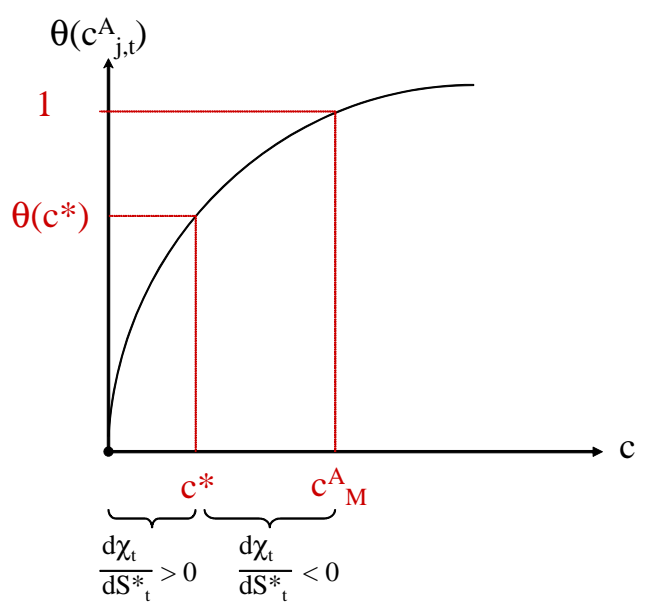

Figure 2: The Impact of Centralized Savings on Inefficiency 


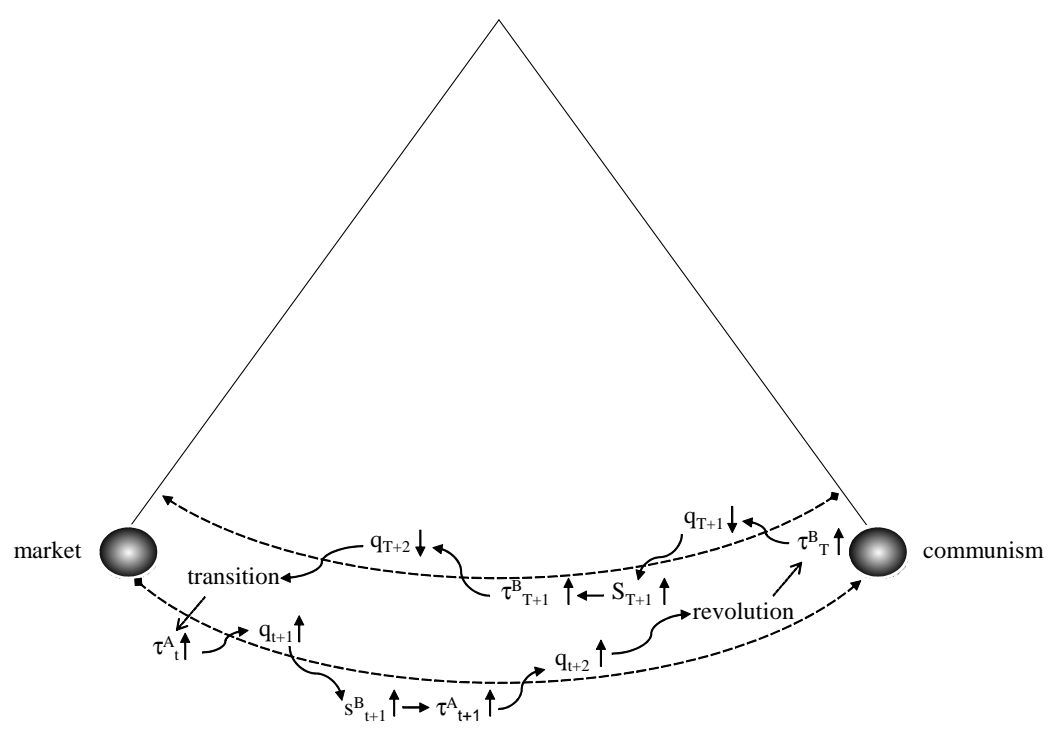

Figure 3: Dynamics of Relative Political Power across Generations

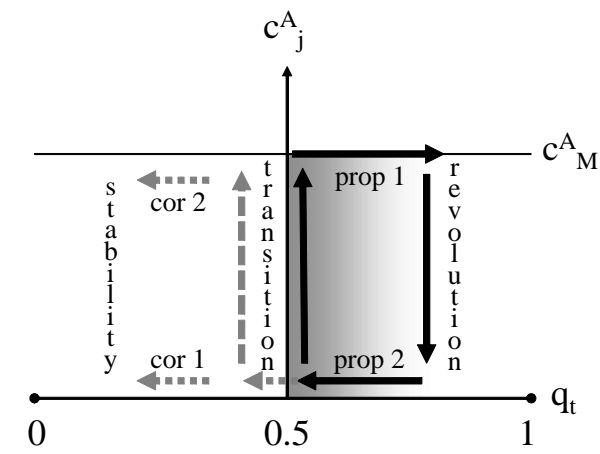

Figure 4: Dynamics of Regime Switches and Stability 